\title{
Análisis Sociolingüístico de la Publicidad
}

\author{
Damián Morales SÁnchez*
}

\section{Universitat Rovira i Virgili, Tarragona, Spain}

\begin{abstract}
This research analyzes the sociolinguistics adequacy in advertisements. The analysis aims to observe how far advertising reflects the covariation phenomena manifested in the different linguistic levels from the conjunction of certains social and contextual variables. The research aims, somehow, to make it clear that sociolinguistics adequacy in ads can increase the effectiveness of advertising communication. We present a qualitative study of a corpus formed by a total of 60 television commercials, selected taking into consideration age and gender of the speaker as the product or service publicized. On the basis of the results obtained, advertising communication reflects both the genderlect and agelect variation. Also, we have observed differences in style and therefore advertising includes the diaphasic variation. However, we perceive the transmission of sociolinguistic stereotypes that encourage creation and difussion of certain sociocultural roles.
\end{abstract}

Keywords: Sociolinguistics, language, variation, advertising.

Resumen. La investigación analiza el nivel de adecuación sociolingüística en los anuncios publicitarios. El análisis realizado tiene como objetivo ver hasta qué punto la publicidad refleja los fenómenos de covariación que se manifiestan en los distintos niveles lingüísticos a partir de la conjunción de determinadas variables sociales

\footnotetext{
* Author's address:

Departament de Filologies Romàniques

Universitat Rovira i Virgili

Av. Catalunya 35, 43002 Tarragona, Spain

E-mail damian.morales@estudiants.urv.cat
} 
y contextuales. El estudio aspira, de alguna manera, a poner de manifiesto que la adecuación sociolingüística en los anuncios puede incrementar la eficacia de la comunicación publicitaria. Se presenta un estudio cualitativo de un corpus formado por un total de 60 anuncios televisivos, seleccionados teniendo en cuenta tanto la edad y el género del hablante como el producto o servicio publicitado. A partir de los resultados obtenidos podemos decir que la comunicación publicitaria refleja tanto la variación generolectal como la genolectal. Asimismo, se observan diferencias en el estilo y, por tanto, podemos decir que la variación diafásica está de algún modo contemplada en publicidad. No obstante, se percibe una transmisión de estereotipos sociolingüísticos que fomentan la creación y la difusión de determinados roles socioculturales.

Palabras clave: Sociolingüística, lenguaje, variación, publicidad.

\section{Introducción}

Nuestro estudio, situado en el ámbito de la sociolingüística variacionista, tiene la intención de aunar a lingüistas y publicistas.

El significativo impacto que los avances tecnológicos han generado en los medios audiovisuales y el crecimiento de la publicidad, gracias a una adaptación acompasada al veloz ritmo de tales innovaciones técnicas, son hechos palmarios. Así, la importancia de la publicidad se refleja en los datos aportados por el Índice Zenith de la agencia Zenith Media, pues solo en 2011 se emitieron 8,2 millones de anuncios en las televisiones españolas, lo cual se traduce en un total de 7.583 minutos al día. Además, el mercado publicitario irrumpe con fuerza en la economía, puesto que la inversión publicitaria crecerá un 5,4\% durante 2016 y si se habla de redes sociales, por ejemplo, la inversión alcanzará los 55,2 millones de euros, suponiendo un incremento del $8 \%$ respecto al año 2015 . Por tanto, la magnitud de la publicidad supone una motivación fundamental para indagar en la disciplina.

Luego, entendiendo la transmisión y divulgación de un mensaje como interés principal de los publicistas, parece extraño el exiguo acercamiento de la publicidad a los diferentes estudios lingüísticos en comparación con la atención prestada a otras disciplinas como pueden ser la psicología, la sociología o la estadística.

Los intentos destinados a conseguir un tratamiento científico de la publicidad no son escasos. A pesar del entusiasmo, parece ser que no es posible hablar de la publicidad como ciencia. En este sentido, es indispensable mencionar las 
palabras de José Ramón Sánchez Guzmán en su Introducción a la teoría de la publicidad y las de Juan Benavides Delgado en Lenguaje publicitario:

Y aunque la evaluación de los diferentes intentos teóricos aún no permita hablar de una "ciencia publicitaria" con autonomía propia, la constitución de esa ciencia ocupa y preocupa a un gran número de investigadores, de cuya labor es posible que se obtengan, en un futuro próximo, las bases de sustentación científica de la técnica publicitaria (Sánchez Guzmán 1979: 33).

La publicidad no es una ciencia; pero su práctica sí afecta a los problemas que las ciencias sociales se cuestionan en torno al sujeto y los modos en que éste y los grupos sociales construyen sus modos de vivir e institucionalizan las conductas y las formas de organización social (Benavides Delgado 1997: 183).

A diferencia de la condición científica, su esencia interdisciplinar ha sido aceptada sin trabas desde su origen. Los principios publicitarios proceden de ramas científicas como la antropología o el derecho, pero su metodología y funcionamiento se construyen a partir de los planteamientos de la psicología, sociología, economía y lingüística (Sánchez Guzmán 1979: 35-36).

La comunicación publicitaria se caracteriza por la denominada persuasión comercial. Por consiguiente, comprender los principios psicológicos implicados en el acto de la sugestión supone la base para la construcción del mensaje. Además, la psicología aporta significativos conocimientos sobre procesos mentales como la atención, la percepción, la memoria, el recuerdo, la imaginación y otros factores relacionados con la conducta humana. Las investigaciones psicoanalíticas son, en parte, causantes de la frenética evolución de la publicidad (Sánchez Guzmán 1979: 36-37).

Por otro lado, si centramos la atención no solo en el individuo, sino en el contexto social donde se ubica, descubrimos la esencial contribución de la sociología. La extracción de determinadas pautas en cuanto al comportamiento social ayuda a una mejor comprensión del público objetivo. Las investigaciones sociológicas enfocadas en el cambio social han sido las más relevantes para la disciplina publicitaria, puesto que permiten reformular los anuncios según la variación social que se experimenta en la comunidad receptora del mensaje (Sánchez Guzmán 1979: 37-38). 
Finalmente, las distintas nociones económicas intervienen en aspectos muy determinantes para el fin de la publicidad, pero relativamente insignificantes para el proceso de comunicación (Sánchez Guzmán 1979: 39).

Ahora bien, consideramos que su carácter interdisciplinar está marcado por una desigual implicación de las disciplinas mencionadas. El interés por las investigaciones psicológicas y sociológicas ha sido tradicionalmente mayoritario en comparación con la importancia concedida a los estudios lingüísticos. De este modo, no resulta extraño hallar ejemplos de anuncios con problemas de carácter sociolingüístico.

La inadecuación del mensaje es fruto no solo de la escasa inclinación hacia las teorías lingüísticas, sino también de la falta de integración de disciplinas elementales para la comunicación como la psicolingüística o la sociolingüística. Es cierto que la linguística puede aportar competencias y estrategias para la creación de un anuncio eficaz. No obstante, recordamos que sus principios teóricos no generan una satisfacción total. Partiendo del principio de la lingüística teórica, según la cual las lenguas son estructuras, la sociolingüística no acepta la homogeneidad de las lenguas. Así pues, la sociolingüística, concebida como el estudio de la lengua en su contexto social, implica una visión más coherente y respetuosa con la realidad.

Juan Benavides Delgado (1997) expresa su preocupación por el lugar que ocupa el lenguaje publicitario en los Nuevos Planes de Estudio. Para su análisis, selecciona la planificación de la Universidad Complutense de Madrid, y concluye con la siguiente idea:

La universidad debe estar atenta a los cambios sociales y definir aquellas cuestiones que el mundo del profesional publicitario nunca se va a replantear -pero que conviene recordarle en la medida en que inciden, directamente, en sus formas de trabajo y organización interna-, bien porque no se cae en la cuenta de que estos problemas existen, bien porque no se está de acuerdo con ellos o no interesa plantearlos. ¡Claro que hay una nueva publicidad! Precisamente porque es la sociedad la que se transforma (Benavides Delgado 1997: 30).

Nuestra motivación reside, por tanto, en la propia naturaleza de la publicidad: su carácter interdisciplinar. Consideramos que la aplicación de principios sociolingüísticos, relacionados esencialmente con los fenómenos de covariación 
que se producen en los distintos niveles lingüísticos -fonético-fonológico, gramatical, léxico y pragmático-discursivo-, según ciertos factores tanto contextuales como sociales - género, edad, clase social, nivel de instrucción y profesión-, contribuirían de manera notable al incremento de la eficacia de la comunicación publicitaria.

Además, presentar una caracterización sociolingüística coherente con la realidad permitiría erradicar el constante uso de tópicos en los medios comunicativos, los cuales fomentan, en su medida, la creación y consolidación de determinados estereotipos. Ya que, si bien Moreno Fernández (1998: 38) manifiesta que "debe valorarse que en los últimos decenios la aceptación y difusión de los medios de comunicación social, especialmente la televisión, está haciendo que el modelo de referencia [sociolingüística] sea el mismo para cualquier hablante de cada comunidad, sea hombre o mujer", pensamos que es relativamente fácil demostrar un uso abusivo de las afirmaciones tradicionales en el ámbito publicitario, además de una fundamentación topicalizada, desleal a la realidad.

El objetivo de la investigación es demostrar la necesidad de hacer uso de los estudios sociolingüísticos en publicidad. Creemos que la adecuación sociolingüística en los anuncios publicitarios puede mejorar de manera clara la transmisión del mensaje -al sentirse el destinatario del anuncio reflejado en el uso del lenguaje que presenta la publicidad- y ello puede tener consecuencias económicas importantes. Nos interesa observar los fenómenos de covariación que se producen en los distintos niveles lingüísticos (fonológico, morfológico, léxico, sintáctico, pragmático) atendiendo tanto a factores contextuales (situación, nivel de formalidad) como a factores sociales (edad, sexo, nivel de instrucción, profesión). Asimismo, a partir de nuestro análisis pretendemos observar los estereotipos sociales (y lingüísticos) que se difunden y fomentan a través de la publicidad.

Se ha trabajado con un corpus de anuncios audiovisuales que han sido analizados sistemáticamente con la intención de determinar su nivel de adecuación sociolingüística. Hemos tenido en cuenta tanto la variación diafásica como la variación diastrática. El corpus está formado por un total de 60 anuncios publicitarios. Teniendo en cuenta que nuestro análisis no pretende ser cuantitativo, el número de anuncios recogidos no es relevante. Nuestro análisis pretende únicamente promover la reflexión con el propósito de abrir la puerta a una vía de investigación posterior que analice con más detalle la implicación de la sociolingüística en la publicidad. 
La selección de los anuncios se ha llevado a cabo a partir de los siguientes criterios:

1. medio utilizado;

2. edad y género del hablante;

3. producto o servicio publicitado.

Siendo conscientes de la significativa variabilidad formal que manifiesta la publicidad, centramos la atención en aquellos anuncios proyectados en televisión por ser uno de los medios masivos más importantes en la actualidad.

Organizamos los anuncios televisivos, teniendo en cuenta las tres etapas generacionales que deseamos examinar -niñez, juventud y edad adulta. Además, hemos intentado recopilar un número equitativo y representativo de anuncios para ambos géneros.

Por último, filtramos los anuncios teniendo en cuenta el producto o servicio publicitado, buscando el máximo número de coincidencias entre las distintas categorías para poder contrastar las posibles diferencias exhibidas en el proceso comunicativo.

El resultado es un corpus que reúne 30 anuncios pertenecientes al género femenino y 30 al masculino, distribuidos en las correspondientes etapas generacionales mencionadas. Con el objetivo de garantizar la efectividad del análisis, este se ha dividido en cinco partes:

1. Identificación de la naturaleza del anunciante y del objetivo que persigue el anuncio, ya que se trata de factores que determinan directamente el contenido del mensaje publicitario.

2. Análisis de las variables sociales que presenta el emisor lingüístico proyectado en el anuncio: género, edad, clase social, nivel de instrucción y profesión. Debe mencionarse, por un lado, que la variable profesión no es aplicable en los emisores de corta edad (niñez) y, por otro, que la presentación de modelos sociolingüísticos no muy precisos en ciertos anuncios provoca que no podamos delimitar con precisión las variables clase social, nivel de instrucción y profesión en determinados casos, pues los límites se muestran difusos.

3. Análisis detallado de las variantes manifestadas en cada nivel lingüístico: fonético-fonológico, gramatical, léxico y pragmático-discursivo. Se examina así el impacto de las variables sociales en el mensaje lingüístico: variación generolectal, genolectal y sociolectal. Todas las consideraciones 
lingüísticas se justifican con sus correspondientes ejemplos extraídos del anuncio concreto.

4. Estudio de la variación diafásica a partir de la clasificación del estilo del mensaje según la propuesta de William Labov (1966: 60-88), estableciendo la siguiente escala ordenada de menor a mayor formalidad: estilo informal, coloquial y formal. Es importante tener en cuenta que los anuncios que reflejan la niñez no pueden someterse al análisis estilístico, pues atendiendo, de nuevo, a las investigaciones de Labov (1964: 77-103) el desarrollo de la variación estilística se produce a partir de los 14 años aproximadamente.

5. Finalmente, observación del cumplimiento de las afirmaciones tradicionales planteadas por la sociolingüística con referencia a la variación generolectal. Las consideraciones han sido extraídas del estudio comparativo de distintas investigaciones sociolingüísticas con la finalidad de obtener una perspectiva lo más completa posible.

En este trabajo, presentamos los resultados obtenidos en nuestro análisis sociolingüístico de la publicidad: en concreto, nos proponemos: 1) Examinar cómo la publicidad refleja la variación generolectal y genolectal; 2) Determinar los fenómenos de covariación en los distintos niveles lingüísticos atendiendo a factores contextuales y a factores sociales; 3) Analizar la variación diafásica a partir de los conceptos de estilo y registro; 4) Reflexionar sobre la adecuación sociolingüística en el uso del lenguaje que presentan los anuncios publicitarios.

\section{Sociolingüística}

Los factores sociales que ejercen una mayor influencia en la variación lingüística y que consideramos en nuestro análisis son: género, edad, clase social, nivel de instrucción y profesión. Es esencial señalar que las variables sociales intervienen de manera singular en cada comunidad:

Los factores sociales no tienen por qué funcionar de igual manera en todas las comunidades: puede que, en un lugar, la edad tenga mayor poder de determinación sobre la lengua o sobre cualquier conducta social que el nivel cultural, que, en otro, el nivel económico provoque más diferencias lingüísticas y sociales que la edad o que, en otro, el sexo sea irrelevante (Moreno Fernández 1998: 34). 
En cualquier caso, partimos de un uso lingüístico natural que se produce en contextos que simulan situaciones reales. Consideramos oportuno remitir a las siguientes palabras de Silva-Corvalán:

La lengua es una forma de conducta social; como tal, creada y moldeada por los seres humanos, desarrolla diferenciaciones internas que corresponden a los parámetros que caracterizan a los diversos subgrupos que constituyen el sistema social. Las correlaciones variacionales entre lengua y sociedad han sido reconocidas desde siempre, pero los estudios cuantitativos del contexto social de la variación lingüística realizados en los últimos años han demostrado en forma sistemática y científica que los factores sociales actúan de manera probabilística en la variación Silva-Corvalán (1989: 68).

\subsection{Variable Género: Variación Generolectal}

La sociolingüística ha concedido un notable protagonismo al factor sexo en sus estudios. No obstante, es lamentable hallar "muchas afirmaciones infundadas, como las que enfrentan el habla de los hombres y mujeres calificando la de estas como conservadora, insegura, sensible, solidaria y expresiva, y la de aquellos como independiente, competitiva y jerárquica" (Moreno Fernández 1998: 36).

Determinadas investigaciones (Wodak \& Benke 1997: 127-150) anulan cualquier intento de subjetividad, analizando las muestras con imparcialidad y rigor (Moreno Fernández 1998: 36). Algunas de las conclusiones estereotipadas son, según Silva-Corvalán (1989: 70), las siguientes:

1. Las mujeres utilizan las variantes lingüísticas de mayor prestigio con más frecuencia que los hombres. La mayor sensibilidad de las mujeres hacia normas de conducta "correcta" se demuestra además en el hecho de que se autocorrigen mucho más que los hombres en contextos formales, aun cuando en el habla casual aparezcan como impulsadoras de una variante innovadora.

2. El habla femenina es más "conservadora" que la masculina y se evalúa como "más correcta". Generalmente, las formas lingüísticas más tradicionales y conservadoras son las consideradas estándar y más prestigiosas.

3. La diferenciación lingüística según el sexo refleja una tendencia general a considerar aceptable o apropiado que los hombres rompan las reglas y que se comporten de manera ruda, agresiva e incluso "más vulgar". El típico 
"doble estándar" se aplica a las mujeres, cuyo comportamiento se espera que sea más cortés, más indeciso y sumiso, más correcto y ajustado a las reglas impuestas por la sociedad.

4. Las mujeres no son frecuentemente impulsadoras del cambio, por las razones dadas en los puntos 1 y 3 , pero [...] esta conducta es a veces contradictoria y puede explicarse en aquellos casos en que el cambio es en la dirección del dialecto estándar; y en otros casos, en relación a las connotaciones evaluativas que ciertas variantes poseen, independientemente de sus estatus de variante estándar o más tradicional.

Los atributos sociolingüísticos relacionados con el género femenino se formalizan mediante: el uso abundante de ciertas formas léxicas de carácter valorativo relacionadas con los sentimientos y la afectividad (divino, monada), de determinados prefijos (súper-), de palabras cotidianas en diminutivo (cafecito, tacita, traguito), de determinadas unidades eufemísticas en diminutivo (braguita), y de truncamientos léxicos con resultado generalmente bisílabo (pelu 'peluquería', ilu 'ilusión', porfa 'por favor') (Moreno Fernández 1998: 37; SilvaCorvalán 1989: 69).

El hablante masculino, definido frecuentemente por oposición, se caracteriza por la ruptura de las normas mediante: el uso de formas innovadoras, léxico relacionado con el poder y la competición, y expresiones más directas, agresivas, incluso vulgares (Silva-Corvalán 1989: 70).

Especialistas como Chambers y Trudgill (1980: 97-98) explican la tendencia del habla femenina a seguir los modelos de prestigio a través de la desigual distribución de poder.

La falta de un lugar destacado en la sociedad hace que las mujeres necesiten marcar su estatus social mediante una conducta específica; por otra parte, la falta de cohesión de las mujeres en las redes sociales las obliga a enfrentarse más a menudo a situaciones de formalidad; [...] finalmente, la educación suele llevar a las mujeres a desempeñar lo que se considera "su" función social siguiendo unas normas de conducta socialmente aceptadas. Se ha añadido a todo eso, que la adecuación a un modelo de prestigio es una estrategia interpersonal cuya finalidad es el mantenimiento de la autoestima en los intercambios sociales (Moreno Fernández 1998: 38-39). 
Posteriormente, Chambers (1995: 102), de nuevo, asocia las diferencias entre el habla de hombres y mujeres con la asignación de distintas funciones socioculturales. Incluso, afirma que las disimilitudes persisten cuando no se tienen en cuenta las diferencias socioculturales:

La mujer tiene unas habilidades verbales mayores y mejores que las de los hombres y que van más allá de las diferencias socioculturales. Las mujeres disponen de una capacidad neurofisiológica verbal que se puede manifestar en forma de diferencias sociolingüísticas, como el uso de un repertorio de variantes más amplio o el manejo de unos recursos estilísticos más ricos que los hombres de sus mismos grupos sociales, aun cuando los atributos "genéricos" sean similares o idénticos (Moreno Fernández 1998: 39).

Es necesario rechazar cualquier distinción biológica, puesto que carece de demostración objetiva y universal. Por otra parte, tampoco se pueden alcanzar reglas universales en cuanto a la diferenciación sociocultural, ya que es completamente variable de unas comunidades a otras (Moreno Fernández 1998: 39). Distintas investigaciones han demostrado que a pesar de la importancia del género (Zernova 2000), en un número considerable de casos, son otros factores los que intervienen en la variación (Moreno Fernández 1998: 36).

\subsection{Variable Edad: Variación Genolectal}

La edad es, con toda seguridad, la variable social más influyente en la variación lingüística de una comunidad de habla. Su estructura lineal y unidireccional facilita el análisis, en contraste con la fluctuación propia de factores como la clase social o la profesión. Además, se trata de una variable constante, puesto que su realidad no se ve alterada por ningún otro factor (Moreno Fernández 1998: 40).

Las actitudes sociolingüísticas van transformándose durante las distintas etapas de la vida de un hablante. La preocupación principal consiste en determinar de manera precisa la extensión de esas etapas, ya que los límites resultan difusos al estar profundamente condicionados por las características concretas de cada sociedad: modelo de organización social, condiciones socioeconómicas, esperanza de vida, etc. (Moreno Fernández 1998: 40). 
La sociolingüística trabaja con tres o cuatro grupos generacionales, dependiendo de la edad que se fije como mínima. Moreno Fernández (1998: 40) apunta que:

La división de grupos puede buscar, bien la agrupación de informantes en categorías de dimensión equivalente, marcando un límite más o menos objetivo cada cierto número de años [...], bien la agrupación en una misma categoría de los informantes que estén viviendo unas circunstancias vitales similares, sabiendo que éstas pueden variar de una comunidad a otra (Moreno Fernández 1998: 40).

Según Moreno Fernández (1998: 44), las cuatro etapas más frecuentes en la vida de un hablante occidental son:

1. formación individual (20-25 años),

2. inicio de la vida profesional (25-35),

3. madurez y máximo rendimiento profesional (35-50/55),

4. y, finalmente, madurez profesional y jubilación (65).

Los niveles lingüísticos más superficiales (léxico, fraseología, discurso) son los que manifiestan de manera más acusada la variación genolectal. Es preciso mencionar el trabajo de López Morales (1993: 117-118) en cuanto a la extracción de un conjunto de patrones a nivel léxico y fraseológico de los hablantes más jóvenes:

1. Estratificación generacional clara en ciertos dobletes léxicos. Las generaciones mayores prefieren el término más antiguo, mientras que los jóvenes muestran una inclinación acusada hacia sinónimos más recientes: sala de fiestas vs discoteca, aeroplano vs avión.

2. Uso abusivo de términos indefinidos y pobres en información: tío, guay, increíble, bueno, bonito.

3. Creación y uso frecuente, entre estos hablantes jóvenes, de metáforas de contenido lúdico-festivo: estar bueno, estar como un tren.

4. Creación de neologismos a través de procedimientos diversos, como el apócope o la adición de sufijos apreciativos: pelu "peluquería", cole "colegio"; litrona, bocata.

5. Adopción de terminología marginal y jergal: sobar por "dormir", currar por "trabajar", papear por "comer". 
La variación genolectal se ha estudiado como reflejo de tres posibles situaciones (López Morales 1993):

1. identidad de ciertos grupos generacionales;

2. autocorrección, especialmente entre los grupos de edad intermedios,

3. fenómeno indicador de la existencia de un cambio lingüístico.

Los fenómenos de identidad generacional se suelen asociar al habla de los jóvenes. El término age-grading alude a las diferencias lingüísticas, habitualmente relacionadas con intensos sentimientos de identidad y solidaridad grupal, características de las diversas edades.

En cuanto a los fenómenos de autocorrección, es interesante destacar que la elevada frecuencia de las variantes innovadoras entre los hablantes más jóvenes disminuye con el paso a edades más adultas.

El motivo más importante parece ser la percepción que el hablante tiene de las ventajas sociales que puede obtener mediante el uso de rasgos lingüísticos considerados de prestigio en la comunidad. En este sentido, los grupos de edades intermedias (20-50 años), inmersos en el mundo de la competencia profesional, económica y de ascenso en la escala social, son los que se espera que presenten perfiles de autocorrección (López Morales 1993: 50).

\subsection{Variable Clase Social: Variación Sociolectal}

El concepto clase social ha sido intensamente debatido por la sociología, desde las primeras propuestas teóricas de importancia procedentes de Karl Marx y Max Weber hasta las más recientes de Hans Gerth, Charles Wright Mills y J. Michael. Por su parte, la sociolingüística concibe el concepto como un significativo inconveniente al configurarse de un modo subjetivo a partir de una realidad multidimensional, en la que destacan parámetros no necesariamente concurrentes como el tipo de profesión, el nivel de rentas o el estatus social (Moreno Fernández 1998: 45-47).

Paradójicamente, el estudio sociolingüístico:

Ha visto las propuestas multidimensionales como una forma suficientemente válida de descubrir diferencias relativas entre individuos, 
porque es una realidad evidente que ciertos usos lingüísticos son más característicos de unos grupos (clases, niveles) que de otros y que las diferencias sociolingüísticas aumentan conforme crece la distancia social entre los miembros de una comunidad (Moreno Fernández 1998: 47).

Las razones que justifican el uso de un modelo multidimensional de estratificación social son: por un lado, la influencia laboviana, y, por otro, la clara conciencia que poseen los hablantes de una comunidad sobre la existencia de una clasificación y distinción de los individuos en estratos, pues "los hablantes se sienten miembros de una clase, no siempre satisfechos, y se consideran capaces de clasificar socialmente a otros hablantes" (Moreno Fernández 1998: 47).

Muestras de la subjetividad en el tratamiento de la variación sociocultural o diastrática son, por ejemplo, las diferencias presentadas entre los modelos clasificatorios de William Labov (1966) y H. López Morales (1983). Labov (1966), en su estudio The Social Stratification of English in New York City, atiende a la división de clases propuesta por J. Michael en 1962 y establece una escala lineal de clasificación del estatus social basada en un índice socioeconómico de 10 puntos formado por la combinación de tres indicadores: el nivel de instrucción, la ocupación y los ingresos familiares. A cada factor le asigna una puntuación de cuatro grados $(0,1,2,3)$, resultando la formación de las siguientes clases sociales: clase media-alta (9 puntos), clase media-baja (8-6 puntos), clase trabajadora (5-2 puntos) y clase baja (1-0 puntos) (Moreno Fernández 1998: 46-47).

A diferencia del modelo anterior, López Morales (1983), en Estratificación social del español de San Juan de Puerto Rico, trabaja con la variable nivel sociocultural, entendiendo "el nivel como una variable de post-estratificación, es decir, como una variable que no se tiene en cuenta para preparar la muestra, aunque sí a la hora de realizar los análisis sociolingüísticos" (Moreno Fernández 1998: 47). Atendiendo a tres parámetros, escolaridad, profesión e ingresos, distingue cuatro niveles socioculturales: medio-alto, medio, medio-bajo y bajo (Moreno Fernández 1998: 47).

La variabilidad en los parámetros atendidos supone, por tanto, una traba para el estudio riguroso de la variación diastrática: del nivel de instrucción, profesión e ingresos atendidos por Labov (1966) y López Morales (1983) a 
la adición de distintos indicadores como el tipo de vivienda, localidad y ocupación del padre por parte de Trudgill (1974) u ocupación de la madre e ingresos promedio familiar de Bentivoglio y Sedano (1993). Diferencias en los parámetros analizados que originan resultados clasificatorios disímiles: cuatro clases en Labov (1966) y López Morales (1983), y cinco en Trudgill (1974) y Bentivoglio y Sedano (1993).

Más allá de las particularidades de cada investigación, se extraen dos conclusiones generales:

1. La asociación entre las clases medias-altas y el mayor uso de las variantes estándares.

2. El comportamiento lingüístico de las clases bajas más inclinado al empleo de las variantes vernáculas.

Finalmente, es un deber señalar la obra Sociolinguistics: An Introduction to Language and Society de Peter Trudgill (1974), quien estudió la relación entre los sociolectos, es decir, "el conjunto de características lingüísticas propias de un grupo, estrato o clase" (Moreno Fernández 1998: 48) y las variedades dialectales, "la manifestación de la lengua en una determinada zona geográfica" (Hudson 1981: 34). Según Trudgill (1974), entre los hablantes de clase baja, donde se localiza un uso poco prestigioso de la lengua, se recogen muestras de las diferentes variedades regionales de un territorio, mientras que en las clases altas está generalizado el uso de la variedad estándar. Por consiguiente, cuanto más bajo es el estrato social de los hablantes, más posibilidades hay de reconocer su procedencia geográfica; identificación que no se produce con facilidad cuando los hablantes pertenecen a las clases más elevadas.

\subsection{Variable Nivel de Instrucción}

La sociolingüística ha demostrado de manera objetiva y rigurosa que "el nivel educativo de los hablantes determina de forma directa y clara la variación lingüística: es normal que las personas más instruidas hagan mayor uso de las variantes que son consideradas como más prestigiosas o que más se ajustan a la norma" (Moreno Fernández 1998: 55).

La variable nivel de instrucción, también denominada educación, estudios o escolaridad, se ha incluido frecuentemente entre los factores que configuran la clase social o el nivel sociocultural. Por consiguiente, a pesar de ser un factor de primer orden, no ha recibido un análisis como variable independiente. 
Concederle un mayor protagonismo no es impedimento alguno para reconocer la relación directa existente entre educación, profesión y clase social: "cuando más preparado se está, cuanto mejor formado, más posibilidades hay de desempeñar profesiones que reporten mayor ingresos económicos, un estatus más alto y más elevadas cotas de poder" (Moreno Fernández 1998: 55).

El nivel de instrucción presenta las mismas dificultades que otras variables: la delimitación objetiva de los niveles y la equiparación de los niveles de comunidades de habla diferentes. Con la finalidad de evitar cualquier tipo de particularidad, la sociolingüística presenta cuatro categorías generales: analfabetismo, enseñanza primaria, enseñanza secundaria y enseñanza universitaria. De todos modos, las investigaciones no responden siempre a tal clasificación, pues, López Morales (1983: 27) distingue ocho grados de escolaridad (0-1 años de escolaridad; 2-6 años de escolaridad; 7-8 años de escolaridad; uno o más años de escuela secundaria; graduado de escuela universitaria; uno o más años de universidad; título universitario pregraduado; título universitario graduado); Samper (1990: 33-35) identifica seis (analfabetos/sin estudios; primer grado; segundo grado, primer ciclo; segundo grado, segundo ciclo; tercer grado, nivel A; tercer grado, nivel B), y Bentivoglio y Sedano (1993: 9) trabajan con nueve (analfabeto; parte de la primaria; años de secundaria/cursos de capacitación; educación secundaria completa/carreras técnicas; medio pregrado/colegio técnico superior; pregrado universitario completo; maestría; doctorado) (Moreno Fernández 1998: 55-56).

De nuevo, la particularidad en la segmentación supone un conflicto a resolver para alcanzar la sistematicidad y la rigurosidad que debe caracterizar a la disciplina sociolingüística. Para ultimar el apartado, remitimos a La teoría del déficit de Bernstein, sociólogo británico que "preocupado muy especialmente por el proceso de socialización de los individuos, ha prestado mucha atención al lugar que ocupa el lenguaje en dicho proceso y lo ha puesto en relación, desde principios básicamente psicolingüísticos, con la clase, la escolaridad y el contexto en que se mueven los hablantes" (Moreno Fernández 1998: 57). Sin perder de vista su origen sociológico, las conclusiones de la investigación son reveladoras en cuanto a la distinción de dos formas de expresión lingüística, de uso de la lengua o de códigos: código restringido y código elaborado. El código restringido se halla en las clases o estratos más bajos, mientras que el código elaborado se ubica en las clases medias. Para Bernstein, todos los hablantes, de cualquier clase social, pueden acceder a un código restringido, pero solo algunos grupos tienen acceso al elaborado; 
en estos últimos el código restringido se reserva para situaciones específicas, generalmente de comunicación familiar. El concepto código se entiende como "modos o patrones de comunicación desarrollados durante el proceso de socialización"; no equivale ni a sociolecto ni a estilo (Moreno Fernández 1998: $57)$.

Siendo conscientes de la importancia que ha proyectado La teoría del déficit en la sociolingüística, decidimos no exponer las múltiples características de cada código y recomendamos la obra de W. P. Robinson (1978), Lenguaje y conducta social, para quienes deseen obtener una perspectiva más completa.

\subsection{Variable Profesión}

Las distintas investigaciones sociolingüísticas han concluido que "la profesión de los hablantes influye de forma directa sobre la variación lingüística. Habitualmente las personas que desempeñan profesiones más prestigiosas hacen mayor uso de las variantes más prestigiosas de una lengua y más ajustadas a la norma" (Moreno Fernández 1998: 60).

La variable profesión ha sobrellevado la misma situación que el nivel de instrucción, puesto que ha sido generalmente incluida entre los factores integrantes de la clase social, sin recibir un análisis independiente y sustancial. En la misma línea que las consideraciones del apartado anterior, es inconcebible negar la estrecha relación entre nivel de instrucción, profesión y clase social.

El establecimiento de las categorías profesionales dentro de una comunidad y la equiparación de las categorías de comunidades diferentes son los objetivos principales en el estudio de la variable profesión. La sociolingüística ha manejado tradicionalmente las categorías profesionales delimitadas por la sociología, que se corresponden con los siguientes siete grupos (Moreno Fernández 1998: 61):

1. obreros sin calificar;

2. obreros con cualificación;

3. empleados medios;

4. pequeños empresarios autónomos;

5. medianos empresarios;

6. profesiones liberales;

7. altos directivos y grandes empresarios 
Sin embargo, no es difícil encontrar discrepancias en cuanto a las categorías resultantes, pues, Bentivoglio y Sedano (1993: 8-9) establecen cinco categorías a partir también de directrices sociológicas (Moreno Fernández 1998: 61):

1. buhoneros y vendedores ambulantes, obreros no especializados urbanos, obreros campesinos, servicio doméstico, servicios no especializados;

2. pequeños comerciantes, secretarios y oficinistas, obreros especializados, artesanos, mecánicos, vendedores en tiendas, cobradores, ayudantes técnicos, policías y guardias, soldados;

3. profesionales universitarios, personal docente de educación media y primaria, pequeños empresarios y productores, mandos intermedios, técnicos, supervisores;

4. profesionales universitarios de libre ejercicio, gerentes medios del sector público y privado, militares con graduación, medianos empresarios y productores, docentes universitarios;

5. altos funcionarios del poder ejecutivo, legislativo y judicial, altos oficiales del ejército, grandes empresarios privados, grandes hacendados, altos ejecutivos del sector público y privado.

Finalmente, como apunta Moreno Fernández (1998: 62): "la covariación de lengua y profesión tiene su reflejo en todos los niveles de la lengua -como en otras variables sociolingüísticas-, pero es en el léxico donde encuentra su expresión más evidente". La relación entre profesión y léxico nos conduce de manera directa al asunto del registro; concepto que atenderemos posteriormente y que también será de especial interés en nuestro análisis.

\section{Publicidad}

\subsection{La Publicidad como Proceso de Comunicación}

La publicidad adquiere una variedad de formas tan amplias que tratar de definir su naturaleza puede resultar una tarea compleja. Hallamos una base común a todo anuncio publicitario y es su estructuración en torno a un proceso comunicativo. De hecho, los componentes del acto comunicativo, tradicionalmente estudiados y organizados en el terreno lingüístico, adoptan una terminología específica en la publicidad.

En el proceso de comunicación publicitaria asociamos el término anunciante con el emisor lingüístico y público objetivo con el receptor. Por otro 
lado, el mensaje que se transmite recibe la denominación genérica de anuncio, mientras que el medio utilizado se conoce generalmente como medio masivo (Ortega 2004: 20). Después de aclarar ciertas cuestiones de terminología, aportamos un conjunto de definiciones para extraer los factores determinantes de la publicidad.

La Asociación Americana de Marketing concibe la publicidad como "toda aquella forma pagada y no personal de presentación y promoción de ideas, bienes y servicios por cuenta de alguien identificado" (Alexander 1963: 9).

Para Aeker y Myers (1984: 17), la publicidad es "un medio de comunicación masiva que involucra a un responsable, el anunciante, quien normalmente contrata a una organización de medios, por ejemplo las cadenas de televisión, para que transmitan un anuncio que en general es creado por una agencia".

Según la Ley General de Publicidad en España publicidad es:

Toda forma de comunicación realizada por una persona física o jurídica, pública o privada, en el ejercicio de una actividad comercial, industrial, artesanal o profesional, con el fin de promover de forma directa o indirecta la contratación de bienes muebles o inmuebles, servicios, derechos y obligaciones. (Ley 34/1988 de 11 de noviembre).

En opinión de Ortega (2004: 22), esta no es una definición totalmente satisfactoria por excluir a todas aquellas campañas publicitarias llevadas a cabo por entidades públicas sin carácter comercial.

Se podrían incluir múltiples definiciones, más o menos adecuadas. Para ampliar la perspectiva, consideramos oportuno recomendar la obra de E. Ferrer, La publicidad (1980), en la que se incluyen doscientas formas distintas de definir la disciplina.

Con el objetivo de alcanzar un estudio riguroso, optamos por la concepción de Enrique Ortega (2004): "la publicidad es un proceso de comunicación de carácter impersonal y controlado que, a través de medios masivos, pretender dar a conocer un producto, servicio, idea o institución con objeto de informar o de influir en su compra o aceptación". A continuación, siguiendo a Ortega (2004: 22-24), analizamos de manera específica cada uno de los factores mencionados: 
1. Proceso de comunicación: se entiende la publicidad como un proceso comunicativo específico en el que entran en juego, convenientemente organizados, los cuatro componentes de la comunicación: anunciante, anuncio, medios masivos y público objetivo.

2. Carácter impersonal: el contacto que se produce entre el anunciante y el público objetivo, es decir, entre emisor y receptor, no es de naturaleza personal. Generalmente, el anuncio se transmite mediante medios a distancia.

3. Comunicación pagada y controlada: las características del anuncio, tales como su extensión, el momento de emisión y su frecuencia de aparición, están controladas por la empresa o institución que paga el anuncio.

4. Medios masivos: los más habituales son los diarios, las revistas, las publicaciones periódicas, Internet, la radio, la televisión, el cine y el medio exterior. El uso de medios masivos permite enviar un mensaje a un inmenso público objetivo con un coste relativamente bajo en comparación con la publicidad basada en la comunicación personal.

5. Producto, servicio, idea o institución: tradicionalmente, la mayoría de anuncios se enfocaban en la venta de un determinado producto tangible. Con el crecimiento publicitario y gracias a su capacidad para llegar rápidamente a un masivo público, no resulta extraño observar anuncios destinados a servicios, ideas e instituciones.

6. Informar, influir en la compra o aceptación: Si bien los anuncios informan sobre la existencia de un producto o servicio, entendemos que subyace la intencionalidad de influir en la compra o generar aceptación.

\subsection{Tipología y Objetivos}

Los anuncios publicitarios se clasifican según un conjunto amplio de criterios, que no siempre pueden resultar satisfactorios. Centramos la atención en los anuncios publicitados en televisión sin discriminar la naturaleza del resto de los criterios clasificatorios. La Tabla 1 presenta una tipología general (Ortega 2004: 26) para comprender la considerable variabilidad formal de la publicidad que mencionábamos en el apartado anterior.

Estudiar los distintos tipos nos permite observar las disimilitudes que aparecen en los objetivos de los anuncios. De todos modos, la publicidad persigue un último objetivo puramente económico. La relación entre publicidad y ventas de un determinado producto o servicio es directa, pero es importante ser conscientes de la repercusión de otros factores como las características 


\begin{tabular}{|c|c|}
\hline CRITERIOS & TIPOS \\
\hline Naturaleza del anunciante & $\begin{array}{l}\text {-De empresas privadas y públicas. } \\
\text {-De asociaciones privadas. } \\
\text {-De administraciones públicas. }\end{array}$ \\
\hline Número de anunciantes & $\begin{array}{l}\text {-Individual. } \\
\text {-Colectiva. }\end{array}$ \\
\hline Actividad del anunciante & $\begin{array}{l}\text {-De fabricantes y productores. } \\
\text {-De intermediarios. }\end{array}$ \\
\hline Naturaleza de los productos & $\begin{array}{l}\text {-De productos. } \\
\text {-De servicios. }\end{array}$ \\
\hline Destino de los productos & $\begin{array}{l}\text {-Dirigida a los mercados de consumo. } \\
\text {-Dirigida a los mercados institucionales. }\end{array}$ \\
\hline Naturaleza del anuncio & \begin{tabular}{|l|}
-Corporativa. \\
-De producto.
\end{tabular} \\
\hline Estructura del anuncio & $\begin{array}{l}\text {-Corporativa. } \\
\text {-No comparativa. }\end{array}$ \\
\hline Alcance de la campaña & $\begin{array}{l}\text {-Local o regional. } \\
\text {-Nacional. } \\
\text {-Intemacional. }\end{array}$ \\
\hline Medio utilizado & $\begin{array}{l}\text {-Prensa. } \\
\text {-Radio. } \\
\text {-Televisión } \\
\text {-Cine } \\
\text {-Otros: exterior, Internet, directa, en el lugar de la } \\
\text { venta. }\end{array}$ \\
\hline Estilo utilizado & $\begin{array}{l}\text {-Instructivo-educativa } \\
\text {-Afectivo-emotiva } \\
\text {-Con ritmo musical. } \\
\text {-Fantástica o irreal. } \\
\text {-Otros: humorística, con dibujos animados... }\end{array}$ \\
\hline
\end{tabular}

Tabla 1. Tipología general de la publicidad.

del producto o el precio. A continuación, siguiendo a Ortega (2004: 36-48), presentamos una clasificación de los objetivos a partir de la naturaleza del anunciante:

1. Objetivos publicitarios de las empresas: dar a conocer un producto o marca; probar un nuevo producto o marca; dar a conocer determinadas características del producto o marca; dar a conocer nuevos usos del producto o marca; incrementar la notoriedad de la marca; crear, mantener o mejorar la imagen de la marca; crear, mejorar o mantener la imagen corporativa; atraer al público a los establecimientos; localizar nuevos clientes potenciales; contrarrestar las acciones de la competencia; favorecer la distribución; modificar hábitos o costumbres; mantener la fidelidad de los compradores y crear un buen ambiente de trabajo. 
2. Objetivos publicitarios de las asociaciones: dar a conocer la existencia de la asociación; dar a conocer determinadas características de la asociación; crear, mantener o mejorar la imagen de la asociación; localizar nuevos miembros; obtener fondos económicos; obtener donaciones no económicas; modificar hábitos y costumbres sociales, y sensibilizar a la población.

3. Objetivos publicitarios de las administraciones públicas: informar; favorecer el conocimiento de las leyes; modificar comportamientos; modificar actitudes; crear, mantener o mejorar la imagen; destacar la existencia o notoriedad de una institución; favorecer la actividad de algunos sectores; conseguir dinero; promocionar servicios.

La publicidad como discurso social utiliza un determinado lenguaje para conseguir sus objetivos; lenguaje que analizaremos sociolingüísticamente en este trabajo.

\section{Análisis Sociolingüístico de la Publicidad}

Presentamos los resultados obtenidos en el análisis sociolingüístico del conjunto de anuncios publicitarios que configuran el corpus.

Uno de nuestros principales objetivos es comprobar si las diferencias generolectales señaladas por la sociolingüística aparecen reflejadas en la publicidad. Nos interesa también considerar la variable edad. Por ello, combinamos ambas variables y presentamos los resultados haciendo referencia a la variación generolectal que se observa en las distintas etapas generacionales. Además de la variación generolectal y genolectal, los resultados tendrán en cuenta las distintas variables sociales expuestas en el marco teórico, con especial atención a la variación diastrática. Asimismo, se hará referencia a la variación diafásica, considerando el uso de registros técnicos y diferentes estilos en publicidad.

Si bien las nociones presentadas en el apartado teórico ofrecen una perspectiva general de la variación generolectal, consideramos necesario presentar aquí una caracterización sociolingüística más detallada tanto del habla femenina como masculina.

La sociolingüística entiende por sexolecto la variedad lingüística que se produce según el sexo del emisor (Calero Fernández 1999: 69). Incluso, hallamos terminología más específica como feminolecto, variedad lingüística de las mujeres, y masculinolecto, variedad de los hombres. 
La existencia de sexolectos es un universal lingüístico. Todas las comunidades de habla presentan, en mayor o menor medida, diferencias en el uso que mujeres y varones hacen del sistema de comunicación verbal y no verbal. [...] Los estudios sociolingüísticos, encargados de analizar cómo pueden afectar en el uso de la lengua determinados condicionamientos sociales -siendo uno de ellos el sexo-, han ratificado las peculiaridades lingüísticas de mujeres y varones (Calero Fernández 1999: 69-70).

Se reconoce, por tanto, la existencia de diferencias lingüísticas que caracterizan a los distintos sexos. El principal problema surge de la confusión entre sexo y género, dado que el primer término se comprende desde una perspectiva biológica como la "condición orgánica, masculina o femenina" (DRAE 2014), mientras que el segundo alude al "grupo al que pertenecen los seres humanos de cada sexo, entendiendo este desde un punto de vista sociocultural en lugar de exclusivamente biológico" (DRAE 2014). Por consiguiente, estimamos más adecuado hablar de variación generolectal, puesto que la demostración científica de la igualdad biológica y neurológica entre hombres y mujeres anula cualquier teoría -como la de Chambers (1995)-, que atribuya algún rasgo diferenciador al sexo.

Además, en nuestra sociedad occidental, parece un tanto arriesgado establecer diferencias lingüísticas considerables entre hombres y mujeres:

En las sociedades occidentales, las diferencias lingüísticas entre el habla femenina y el habla masculina son pequeñas; incluso, los hablantes no somos conscientes de que existen, y menos aún de que las llevamos constantemente a la práctica (Calero Fernández 1999: $72)$.

El estudio objetivo y riguroso, que debe formar parte de cualquier disciplina, conduce al rechazo contundente de afirmaciones insostenibles como la siguiente:

En general, se considera a la mujer por naturaleza parlanchina, poco lúcida en sus argumentaciones, incapaz de cumplir su palabra y de guardar un secreto, y sobre todo, embaucadora; por oposición, el varón es comedido, inteligente, honrado, discreto e ingenuo. Estas ideas preconcebidas -resultado de una clara y radical separación de 
papeles-, permiten justificar en todas estas comunidades que se niegue a las mujeres el uso de la palabra (Calero Fernández 1999: 70-71).

Resulta indispensable el análisis exhaustivo de las investigaciones sociolingüísticas realizadas hasta el momento para reivindicar la percepción de que las diferencias generolectales son mínimas en nuestro contexto social y responden más bien a la conjunción de múltiples variables sociales (edad, clase social, nivel de instrucción, profesión). Distintos autores -Silva-Corvalán (1989), López Morales (1993), Moreno Fernández (1998), Zernova (2000), entre otros-, han registrado las aserciones más representativas del habla femenina establecidas por la sociolingüística. Sin embargo, los manuales no determinan con tanta precisión el habla masculina, sino que la conciben por mera oposición a la femenina.

La Tabla 2 ofrece una caracterización sociolingüística del habla femenina. La sensación es que tal caracterización sociolingüística se muestra impregnada de ciertos tintes estereotipados que trataremos de analizar en el ámbito publicitario. Para ello, es necesario apuntar que el género femenino se representa en la publicidad a partir de tres modelos:

1. publicidad estereotipada: roles tradicionales del hombre y la mujer;

2. publicidad idealizadora de la belleza femenina;

3. publicidad cosificadora de la sexualidad femenina (García Pérez 2009: 59).

En tanto deseamos demostrar el uso de determinados estereotipos sociolingüísticos, atenderemos con especial disposición al primer modelo, pero sin descuidar el resto.

Los estereotipos son "marcadores sociolingüísticos que la comunidad reconoce conscientemente como tales, pero que no corresponden necesariamente a la actuación lingüística real de los hablantes. El estereotipo es citado como un rasgo definitorio de un grupo social y generalmente se percibe, erróneamente, como categórico" (Silva-Corvalán 1989: 68).

La caracterización sociolingüística presentada en la Tabla 2 se utilizará en los siguientes apartados para analizar en qué proporción hombres y mujeres utilizan las diferentes características que se atribuyen al género femenino. Con la finalidad de facilitar la visualización del contenido, expresamos los resultados extraídos a través de los gráficos correspondientes. 


\begin{tabular}{|c|}
\hline Caracterización sociolingüística del habla femenina \\
\hline $\begin{array}{l}\text { 1. PRESTIGIO: uso de las variantes lingüísticas de mayor prestigio (Silva-Corvalán 1989:70; López Morales } \\
\text { 1993: 122; Moreno Fernández 1998:38; Zernova 2000: 1). }\end{array}$ \\
\hline $\begin{array}{l}\text { 2. CORTESÍA: mayor cortesía, correccióny adecuación a la norma, exhibidas, por ejemplo, a partir de actos de } \\
\text { habla y estrategias discursivas destinadas a proteger la imagen del interlocutor (Silva-Corvalán 1989: 70; López } \\
\text { Morales 1993: 125; Moreno Fernández 1998: 38; Zernova 2000: 1). }\end{array}$ \\
\hline $\begin{array}{l}\text { 3. INTENSIFICACIÓN: tendencia a la intensificacióny a la expresividad a partir de adverbios intensificadores } \\
\text { en -mente, sufijo-ísimo, prefijos super-, hipe-, re-y elativos léxicos como maravilloso, fantástico, precioso, } \\
\text { extraordinario, fatal, etc.(Moreno Fernández 1998: 38; Zernova 2000: 4). }\end{array}$ \\
\hline $\begin{array}{l}\text { 4. DUPLICACIÓN INTENSIFICADORES: duplicación de los semas elativos, que se manifiesta en la reunión de } \\
\text { dos o más indicios del supremo grado de cualidad: el léxico (adverbio intensificador) y el morfológico (sufijo), } \\
\text { muy traviesillo; el sintáctico (iteración) y el morfológico (sufijo), es rapidito rapidito; dos léxicos (dos } \\
\text { adverbios, o un adverbio y un adjetivo de valor elativo), completamente horroroso. Tendencia a la iteración del } \\
\text { mismo intensificador con el fin de crear más fuerza expresiva: muy muy muy generoso (Yelena Zernova } 2000 \text { : } \\
\text { 5). }\end{array}$ \\
\hline 5. SINTAXIS SIMPLE: construcciones sintácticas simples y breves (Zernova 2000:4). \\
\hline $\begin{array}{l}\text { 6. UNIDADES VALORATIVAS: frecuentes unidades valorativas. Calificación del objeto según el modelo } \\
\text { atributivo, formando la proposiciónconel determinante en calidad del núcleo informativo: Pepita es guapa } \\
\text { (Zernova 2000: 4). }\end{array}$ \\
\hline $\begin{array}{l}\text { 7. LÉXICO POSITIVO: preferencia evidente por el léxico de sentido positivo, rehusando las características } \\
\text { negativas (Zernova 2000: 4). }\end{array}$ \\
\hline $\begin{array}{l}\text { 8. DIMIINUTIVOS: unidades léxicas de alta frecuencia en diminutivo: cafecito, pequeñito (Silva-Corvalán } 1989 \text { : } \\
\text { 69; Moreno Fernández 1998:37; Zemova 2000:5); formas eufemisticas en diminutivo: braguitas (Moreno } \\
\text { Fernández 1998: 37). }\end{array}$ \\
\hline $\begin{array}{l}\text { 9. TRUNCAMIIENTOS: truncamientos léxicos con resultado generalmente bisílabo: pelu 'peluqueria', ilu } \\
\text { 'ilusión' (Moreno Fernández 1998: 37). }\end{array}$ \\
\hline $\begin{array}{l}\text { 10. EXPRESIVIDAD: tendencia a la ins eguridad y expresividad. La menor seguridad se refleja en la preferencia } \\
\text { que manifiestan, por ejemplo, en el empleo atributivo del adjetivo, que puede considerarse como un paso } \\
\text { introductorio, previo, antes de emitir unjuicio más categórico (Moreno Fernández 1998:38; Zernova 2000: 1) }\end{array}$ \\
\hline
\end{tabular}

Tabla 2. Caracterización sociolingüística del habla femenina.

\subsection{Variación Generolectal en Hablantes de Corta Edad}

A continuación, tratamos la variación sociolingüística en los grupos de corta edad, esto es, pertenecientes a la etapa generacional de la niñez. El asunto de la edad mínima que han de tener los hablantes para poder ser objeto de estudio sociolingüístico ha recibido tratamientos distintos: Bentivoglio y Sedano (1993) manejan una edad mínima de 14 años; Etxebarría (1985), de 15 años; Alba (1990) y Perissinotto (1972), de 16 años; Ueda (1982), de 18 años; y López Morales, Martínez Martín y Samper (1990), de 20 años. Por tanto, observamos que la sociolingüística no suele estimar la recogida de datos de informantes menores de 14 o 15 años, a no ser que su objetivo sea el análisis de 
los cambios lingüísticos en tiempo aparente, donde es recomendable el estudio de hablantes de 8 años en adelante, tal y como apunta Labov (1996: 104) (Moreno Fernández 1998: 42).

En tanto la publicidad presenta con relativa frecuencia anunciantes menores de 14 años, consideramos que la sociolingüística debe manifestarse al respecto a través de la aportación de resultados objetivos y sistemáticos que respondan a una caracterización coherente de la realidad. La adquisición del dialecto y sobre todo del sociolecto, esto es, la variedad lingüística del grupo social al que pertenece el hablante, nos aporta relevante información para nuestro objetivo.

En este sentido, Labov (1964: 77-103) propuso una división periódica de seis fases para la adquisición del inglés estándar, incluidas todas sus variedades regionales, sociales y estilísticas. Labov concibe la adquisición "como un proceso de aculturación o de alejamiento de los usos adquiridos en la adolescencia y una adecuación al modelo predominante entre los miembros adultos de la comunidad" (Moreno Fernández 1998: 41) y establece las siguientes etapas:

1. Adquisición de la gramática básica, en la primera infancia.

2. Adquisición del vernáculo, entre los 5 y los 12 años.

3. Desarrollo de la percepción social, entre los 14 y los 15 años.

4. Desarrollo de la variación estilística, a partir de los 14 años aproximadamente.

5. Mantenimiento de un uso estándar coherente, en la primera etapa adulta.

6. Adquisición de todos los recursos lingüísticos; se produce en las personas educadas y especialmente preocupadas por el uso de la lengua.

Moreno Fernández (1998: 41) apunta que la primera fase (1-2) -objeto de nuestro análisis- se produce bajo la influencia directa de los padres, destacando el papel esencial de la madre en el desarrollo lingüístico, y de la familia más inmediata; la segunda (3-4) recibe el influjo de los amigos y compañeros de estudio; la tercera (5) supone la influencia de hablantes adultos, y, finalmente, la cuarta (6) requiere contactos sociales de distinta índole.

La sugestión de universalizar las seis etapas de Labov ha dado origen a un intenso debate que aún permanece abierto. Romaine (1984: 85) critica la imprudencia de oponer jóvenes a adultos sin atender a las diferencias sociales que pueda haber entre unos jóvenes y otros; Chambers destaca la imposibilidad de diferenciar entre lo que Labov denomina gramática básica y vernáculo; y, por último, investigadores como Reid (1978: 158-171) o Wolfram (1989: 
310-332) demuestran la posibilidad de hallar diferencias diatópicas, diafásicas, diastráticas y generolectales en niños de tres, seis, ocho, diez o doce años, asumiendo que la adquisición de una variedad lingüística viene determinada por factores biológicos, pero también de manera significativa por factores sociales (Moreno Fernández 1998: 41-42).

Antes de presentar nuestro análisis sociolingüístico, nos referimos al concepto de maternés: "variedad que utilizan todas las 'madres' del mundo cuando hablan a sus hijos" (Anula Rebollo 1998: 36). Las características más relevantes del maternés aparecen determinadas con precisión en Anula Rebollo (1998: 36):

1. La pronunciación es más cuidada y se caracteriza por poseer un timbre elevado, una entonación exagerada y una declamación más lenta (con pausas más numerosas y más largas).

2. Las emisiones suelen ser breves (del orden de tres veces por debajo de la de los adultos).

3. Los enunciados suelen estar bien formados (evitando los cambios de construcción, las elisiones, etc.) y a menudo se repiten.

4. El léxico se simplifica: se limita el número de palabras, abunda el uso de ciertos recursos morfológicos (diminutivos) y la repetición de piezas léxicas.

5. El tema de la enunciación se centra en las circunstancias del "aquî" y "ahora" que afectan al niño.

Contemplamos la posibilidad de que los rasgos lingüísticos presentados en el maternés puedan covariar en función de factores sociales, provocando, por consiguiente, que la adquisición básica que se produce en la primera infancia (etapa 1 del proceso de adquisición propuesto por Labov) también pueda presentar matices distintos en función de variables como el "sexo" del niño. De hecho, estimamos que las distinciones lingüísticas observadas en los anuncios cuyos emisores son hablantes de corta edad contribuyen significativamente a la construcción de determinados roles sociales asociados al género.

Los resultados de nuestro análisis apuntan a que las diferencias lingüísticas se manifiestan con mayor intensidad en los hablantes de corta edad. El fenómeno se relaciona directamente con la construcción de los roles socioculturales. Así, 
- el género femenino se representa mediante la exposición de valores asociados a la imagen física (véanse los anuncios $2,4,10)$, al hogar $(5,9)$ o al cuidado familiar $(1,3,6,7,8)$;

- mientras que la violencia $(31,32,34,36)$, la ruptura de las normas $(37$, $38)$ y el desafío $(33,35)$ son atributos exhibidos en la caracterización del género masculino.

Se produce, por tanto, la difusión de estereotipos inadecuados, que adquirirán distintos matices formales en las demás etapas vitales del hablante.

Parece evidente que la sociología debe cooperar con la publicidad para intentar evitar caracterizaciones sociales inapropiadas, pero también es necesario que la sociolingüística se posicione al respecto, en tanto la difusión del estereotipo se produce a través de la realización lingüística. Muestra de ello son los siguientes resultados, pues los emisores femeninos de corta edad se representan a partir de una media de 6 rasgos del habla femenina, mientras que los emisores masculinos de corta edad se caracterizan a través de una media de 3-4 rasgos, estableciéndose así una cierta oposición entre la variedad lingüística de ambos géneros.

Los porcentajes demuestran que los anuncios publicitarios expresan la variación generolectal en la niñez a partir de:

- La cortesía, corrección y adecuación a la norma: pues son rasgos exhibidos por la totalidad de los emisores lingüísticos femeninos de corta edad frente al $12,5 \%$ de los emisores masculinos;

- El uso de frecuentes unidades valorativas: los resultados muestran que en el $90 \%$ de los mensajes publicitarios representados por niñas se utilizan constantes calificaciones atributivas, relacionadas principalmente con la valoración del plano físico, en contraste con el $25 \%$ que presentan los niños;

- La preferencia por el léxico de sentido positivo: plasmada en el total de los hablantes femeninos en comparación con el $25 \%$ de los emisores masculinos. En este sentido, la diferenciación generolectal también se aprecia en el uso de eufemismos en el habla femenina en contraste con la masculina,

- Y aún de forma más marcada, a través del uso de unidades léxicas de alta frecuencia en diminutivo: el fenómeno se produce en un $50 \%$ de los mensajes femeninos en contraposición a la ausencia total de diminutivos y truncamientos léxicos en los anuncios masculinos. 
Por otro lado, los resultados apuntan hacia ciertas tendencias similares entre ambos géneros, las cuales pueden considerarse, en algunos casos, contrarias a los planteamientos sociolingüísticos relacionados con la variación generolectal. Así, se percibe un uso equitativo entre ambos géneros en:

- Las variantes lingüisticas de mayor prestigio: la diferencia tan solo supone un $7,5 \%$ de los anuncios analizados.

- La tendencia a la intensificación y duplicación de intensificadores: ambos géneros presentan una tendencia acusada a la intensificación, un $60 \%$ en el género femenino y un 62,5\% en el masculino; produciéndose así una leve incoherencia con los planteamientos tradicionales que relacionan la intensificación exclusivamente con el habla femenina. En cuanto a la duplicación de los intensificadores parece manifestarse de manera poco frecuente tanto en el habla femenina como en la masculina.

- Construcciones sintácticas simples: se trata de una consecuencia directa de la corta edad de los emisores lingüísticos, ya que las construcciones sintácticas son de carácter simple durante los primeros estadios de la adquisición del lenguaje.

- Y la tendencia a la expresividad: la manifestación de mensajes expresivos es de alta frecuencia en los anuncios de ambos géneros, $90 \%$ en el género femenino y $100 \%$ en el masculino. No obstante, mientras que la expresividad femenina se vincula directamente con la inseguridad; la masculina se asocia, de manera general, a conductas de desafío y competencia.

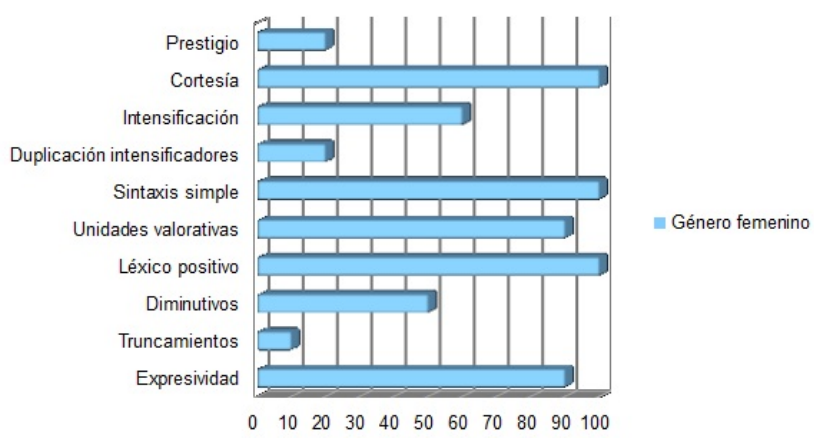

Fig. 1. Características del habla femenina en las niñas. 


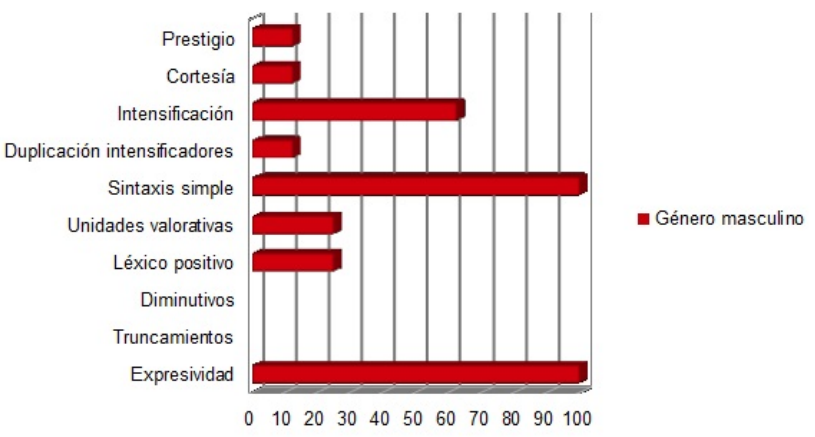

Fig. 2. Características del habla masculina en los niños.

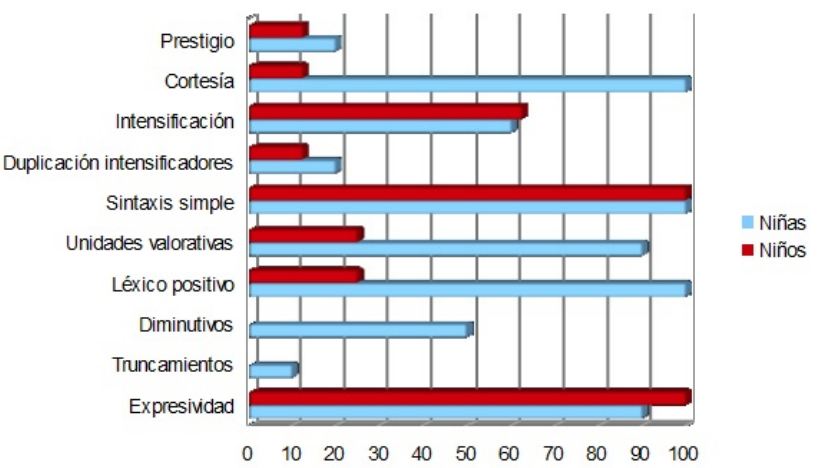

Fig. 3. Variación generolectal en los hablantes de corta edad.

La diferenciación generolectal que presenta la publicidad para las edades cortas se traza de un modo más superficial, afectando principalmente al nivel léxico y morfosintáctico. No obstante, como puede observarse en la Tabla 3, se hallan distinciones en todos los niveles lingüísticos:

- Fonético-fonológico: la expresividad es un rasgo presentado por los mensajes publicitarios de ambos géneros. Sin embargo, la expresividad femenina se relaciona con los sentimientos y la efectividad, percibiéndose 
así una estrecha vinculación con la cortesía, mientras que la entonación expresiva del habla masculina exhibe justo lo contrario, esto es descortesía y agresividad.

- Gramatical: el discurso femenino se formaliza a partir de construcciones morfológicas relacionadas con el uso de sufijos diminutivos y de formas apocopadas, así como a partir de las intensificaciones expresadas mediante procedimientos gramaticales. En contraposición, el habla masculina destaca por la ausencia de formas diminutivas y apocopadas.

- Léxico: es con toda probabilidad el nivel que refleja una mayor variación generolectal, puesto que el habla femenina exhibe una tendencia acusada al uso de elativos léxicos, unidades expresivas carentes de información y unidades léxicas valorativas relacionadas generalmente con la imagen, incluso con el cuidado familiar y el hogar. En cambio, el habla masculina manifiesta, en menor medida, el uso de ciertos elativos léxicos y de unidades léxicas carentes de información, y sobre todo se caracteriza por la aparición constante de léxico asociado a la agresividad y a la competitividad.

- Pragmático-discursivo: las implicaciones pragmáticas del discurso son totalmente opuestas. El género femenino se refleja a partir de discursos con implicaciones pragmáticas vinculadas con la belleza, la sensibilidad, el cuidado familiar y el hogar; mientras que los discursos masculinos potencian la agresividad, el desafío y la violencia. 


\begin{tabular}{|c|c|c|}
\hline Nivel lingüístico & Género femenino & Género masculino \\
\hline Fonético-fonológico & $\begin{array}{l}\text {-Entonación expresiva asociada a la } \\
\text { afectividad y a la cortesía: iqué } \\
\text { guapos están!, iqué bien cuidas a } \\
\text { Nenuco! }\end{array}$ & $\begin{array}{l}\text {-Entonación expresiva asociada a la } \\
\text { agresividad y a la descortesía: ¡ ¿quieres } \\
\text { más?!, ;al ataque! }\end{array}$ \\
\hline Gramatical & $\begin{array}{l}\text {-Construcciones morfológicas a partir } \\
\text { del sufijo diminutivo: perritos, } \\
\text { hermanita, cositas, camita, cocinita. } \\
\text {-Eufemismos en diminutivocaquita. } \\
\text {-Intensificación a partir del prefijo } \\
\text { super-: superlinda. } \\
\text {-Intensificación a partir de } \\
\text { procedimientos gramatical: tan } \\
\text { bonito, la más bonita, muchas cositas. } \\
\text {-Formas apocopadas: pelu. } \\
\text {-Iteración del mismo intensificador: } \\
\text { muy muy amigas. } \\
\text {-Estructuras sintácticas simples: } t u \\
\text { Nenuco está malito, Barbie baña a } \\
\text { sus perritos. }\end{array}$ & $\begin{array}{l}\text {-Ausencia de diminutivos. } \\
\text {-Intensificación a partir del prefijosuper-: } \\
\text { superrápida. } \\
\text {-Ausencia de formas apocopadas. } \\
\text {-Estructuras sintácticas simples: hemos } \\
\text { conquistado el castillo, echad el ancla }\end{array}$ \\
\hline Pragmático-discursivo & $\begin{array}{l}\text {-Variantes léxicas de mayor prestigio: } \\
\text { look. } \\
\text {-Elativos léxicos: fantástica, genial. } \\
\text {-Unidades expresivas, carentes de } \\
\text { información: iguau! } \\
\text {-Unidades léxicas valorativas } \\
\text { relacionadas mayoritariamente con la } \\
\text { imagen: guapos, bonita, divina. } \\
\text {-Unidades léxicas relacionadas con el } \\
\text { hogar y el cuidado familiar: cocina, } \\
\text { casa, baño; está malito, no me come. } \\
\text {-Discursos con implicaciones } \\
\text { pragmáticas vinculadas con la belleza } \\
\text { (ser una princesa) y sensibilidad, el } \\
\text { hogar (qué ordenada la cocind) y el } \\
\text { cuidado familiar (no me come). }\end{array}$ & $\begin{array}{l}\text {-Elativos léxicos: fascinante, genial. } \\
\text {-Unidades expresivas, carentes de } \\
\text { información: iguau! } \\
\text {-Unidades léxicas relacionadas con la } \\
\text { competitividad: poder, fuerza, rival, } \\
\text { campeón. } \\
\text {-Unidades léxicas relacionadas con la } \\
\text { agresividad: atacar, luchar, conquistar. } \\
\text {-Discursos con implicaciones pragmáticas } \\
\text { vinculadas con la competitividad (ser el } \\
\text { campeón), la agresividad (al ataque) y el } \\
\text { desafio (desafia las leyes). }\end{array}$ \\
\hline
\end{tabular}

Tabla 3. Caracterización sociolingüística de los hablantes de corta edad en publicidad. 
En conclusión, el género femenino se refleja a partir de la cortesía, la corrección, las unidades valorativas, el léxico de sentido positivo, los diminutivos y la expresividad sensible; mientras que el masculino desafía a las normas, apenas realiza valoraciones físicas, rehúsa los valores positivos, no presenta ninguna unidad léxica en diminutivo y no expresa ningún tipo de sensibilidad o inseguridad, justo al contrario, promueve valores de lucha y competitividad.

Nos parece oportuno remitir, a modo de cierre, a un anuncio de la empresa privada $L i d l$ que refleja a la perfección la construcción de los roles socioculturales comentados al inicio del apartado. En él, un niño de unos 4-5 años está hablando con un oso de peluche vestido de Papá Noel, diciéndole exactamente: "este año mi hermana ha sido muy buena y me gustaría que le trajeras ..." Al día siguiente, los dos hermanos van a abrir los regalos llenos de ilusión y la niña se sorprende porque le han traído "comida para mi cocinita", mientras que al niño le han dejado "un juego de construcción". Diferencias socioculturales que como advierte el anuncio de ING Direct: "ya vivimos demasiado condicionados".

Parece ser, por tanto, que las diferencias generolectales se perciben en publicidad ya desde edades muy cortas y se desarrollan con distintas estrategias, como veremos más adelante, en las etapas sucesivas. Es cierto que determinados rasgos pueden y deben atribuirse a la variable edad, como la construcción de estructuras sintácticas simples o la expresividad, pero el disímil uso de las unidades léxicas y las distintas connotaciones pragmáticas nacen directamente del claro objetivo de los publicistas de marcar distancia entre ambos géneros.

\subsection{Variación Generolectal en Hablantes Jóvenes}

Los estereotipos sociolingüísticos adquieren una dimensión más profunda en los hablantes jóvenes, pues no solo se manifiestan con intensidad en los niveles lingüísticos más superficiales como el léxico, sino que puede observarse una transmisión de valores radicalmente opuestos en el nivel pragmáticodiscursivo. En este sentido, denunciamos la infravaloración del género femenino a partir de connotaciones sexistas que deberían erradicarse. Pruebas de ello son los anuncios de Alfa Romeo, Kalia Vanish, Bosch y Qé crack!.

Tras el análisis, observamos que el género femenino exhibe una media de 5-6 rasgos propios del habla femenina; en contraste con los 2 de media que aparecen en los hablantes masculinos. Si bien la variación generolectal se marcaba con una significativa intensidad en los hablantes de corta edad, en 
la juventud se percibe una sutil reducción de ciertas diferencias. La posible explicación a este hecho se encuentra en que los publicistas focalizan deliberadamente su atención sobre los rasgos de identificación generacional, es decir, del habla juvenil por encima de las marcas generolectales. De todos modos, se siguen apreciando diferencias muy relevantes en los siguientes puntos:

- La mayor cortesía, corrección y adecuación a la norma del género femenino frente al masculino: un $80 \%$ de los mensajes femeninos presentan mensajes corteses y adecuados, en comparación con el $40 \%$ de los anuncios masculinos.

- Tendencia a la intensificación y a la duplicación de intensificadores: un $40 \%$ de los anuncios femeninos exhibe una tendencia a la iteración de los intensificadores con el fin de crear más fuerza expresiva; recurso inexistente en los mensajes masculinos.

- Frecuencia de las unidades valorativas: se perciben constantes calificaciones en un $80 \%$ de los anuncios femeninos frente al escaso $10 \%$ de los masculinos.

Al margen de estas disimilitudes, las actitudes lingüísticas son muy similares en cuanto al uso de variantes lingüisticas prestigiosas, al comportamiento sintáctico y a la expresividad.

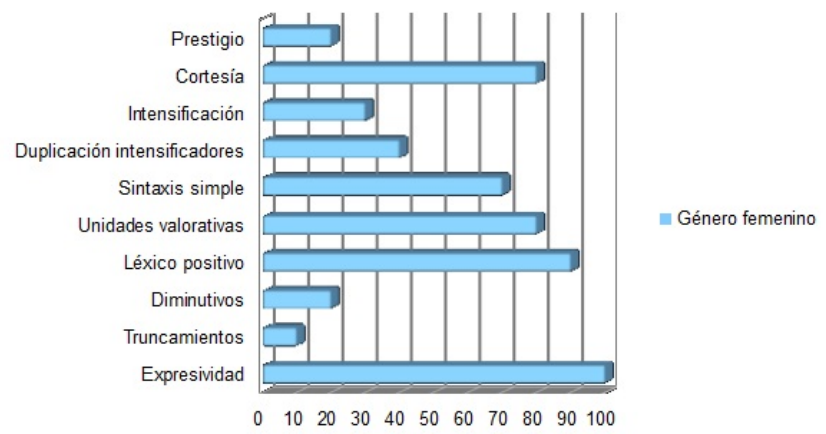

Fig. 4. Características del habla femenina en hablantes jóvenes femeninos. 


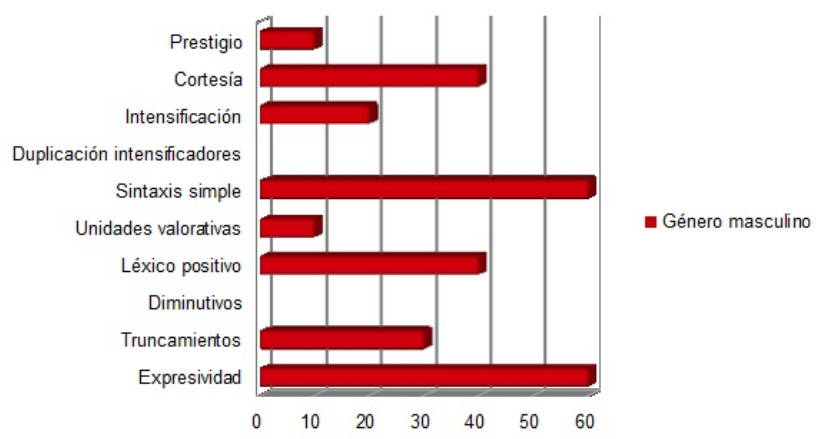

Fig. 5. Características del habla masculina en hablantes jóvenes masculinos.

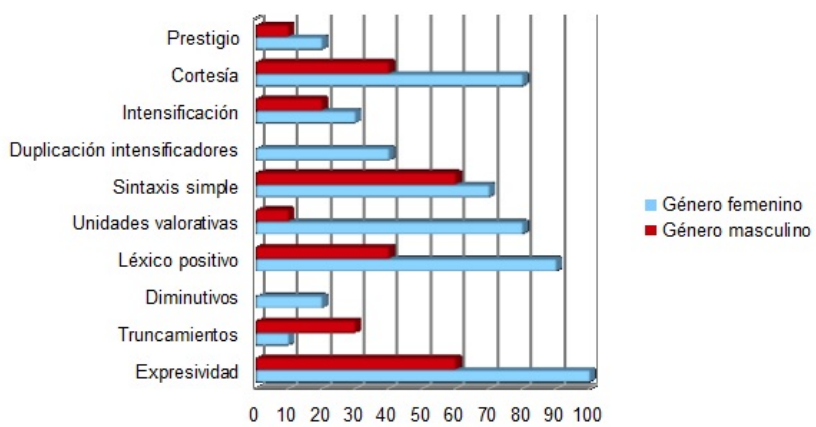

Fig. 6. Variación generolectal en los hablantes jóvenes.

De nuevo, para obtener una perspectiva más completa, exponemos los rasgos sociolingüísticos más relevantes hallados en los distintos niveles lingüísticos:

- Fonético-fonológico: la entonación expresiva se vincula con la cortesía en el habla femenina, mientras que en la masculina se relaciona de manera opuesta con la descortesía y la seguridad del emisor.

- Gramatical: el género femenino se refleja a partir de construcciones diminutivas, formas apocopadas, intensificaciones y duplicaciones de intensificadores frecuentes. En contraposición, los emisores masculinos no expresan unidades en diminutivo y tanto las intensificaciones como las 
formas apocopadas son poco habituales. Debe mencionarse que los truncamientos léxicos y el uso de la apócope son rasgos que pueden relacionarse con la expresión juvenil.

- Léxico: de nuevo es el nivel que presenta una mayor diferenciación generolectal. El género femenino manifiesta una tendencia mayor al uso de variantes léxicas prestigiosas, de elativos léxicos, truncamientos léxicos y metáforas lúdico-festivas de carácter coloquial. A diferencia, el género masculino emplea variantes léxicas de menor prestigio, demostrando una cierta inclinación por formas léxicas informales, expresiones de carácter vulgar y unidades carentes de información. Además, la competitividad está muy presente en el léxico masculino, mientras que la imagen suele ser el eje del discurso femenino.

- Pragmático-discursivo: las estrategias discursivas también exhiben una determinada covariación en función del género del hablante. Para representar el género femenino la publicidad utiliza mecanismos conversacionales solidarios, estrategias discursivas de carácter interrogativo y, desafortunadamente, discursos con implicaciones pragmáticas sexistas, relacionadas con la infravaloración y la cosificación de la mujer. En cambio, el género masculino se presenta mediante mecanismos conversacionales descorteses, estrategias discursivas de carácter imperativo o informativo-explicativo y discursos con implicaciones vinculadas con la seguridad a partir de actitudes vulgares. 


\begin{tabular}{|c|c|c|}
\hline Nivel lingüístico & Género femenino & Género masculino \\
\hline Fonético-fonológico & $\begin{array}{l}\text {-Entonación expresiva asociada a la } \\
\text { valoración y a la cortesía: isiempre } \\
\text { estamos de acuerdo!, iqué suave!, iqué } \\
\text { gusto el verano! }\end{array}$ & $\begin{array}{l}\text {-Entonación expresiva asociada a la seguridad } \\
\text { y a la descortesía: iay, mamá, qué plasta! ;vas } \\
\text { a esperar ni a esperar!, ;venga, tú puedes! }\end{array}$ \\
\hline Gramatical & $\begin{array}{l}\text {-Construcciones morfológicas a partir } \\
\text { del sufijo diminutivo: ayudita, paellitas. } \\
\text {-Intensificación a partir del prefijo } \\
\text { extra-: extrasuave. } \\
\text {-Duplicación de intensificadores: } \\
\text { mucho más suave. } \\
\text {-Intensificación a partir de la iteración } \\
\text { de la misma unidad: daño, mucho daño, } \\
\text {-Estructuras sintácticas simples: yo soy } \\
\text { Giulietta; ¿quieres ser natural? }\end{array}$ & $\begin{array}{l}\text {-Ausencia de diminutivos. } \\
\text {-Intensificación a partir de sufijos } \\
\text { aumentativos: eurazos. } \\
\text {-Formas apocopadas: insti, mates, moto. } \\
\text {-Estructuras sintácticas simples: este año va en } \\
\text { serio; mañana a las siete salgo. }\end{array}$ \\
\hline Léxico & $\begin{array}{l}\text {-Variantes léxicas de mayor prestigio: } \\
\text { spinning, glossy. } \\
\text {-Elativos léxicos: increible, total, } \\
\text { genial, perfecto. } \\
\text {-Truncamientos léxicos: pichoncito. } \\
\text {-Metáforas lúdico-festivas: estar bueno; } \\
\text { recursos ingeniosos: } 85 \% \text { cacao y 100\% } \\
\text { necesario para que te olvides, } \\
\text { expresiones coloquiales: es una pasada, } \\
\text { fue un flechazo. } \\
\text {-Unidades léxicas valorativas } \\
\text { relacionadas mayoritariamente con la } \\
\text { imagen y la seguridad: natural, } \\
\text { auténtica, suave; fácil, cómodo. }\end{array}$ & $\begin{array}{l}\text {-Variantes léxicas de menor prestigio. } \\
\text { Inclinación por formas léxicas informales: } \\
\text { plasta, pasta (dinero). } \\
\text {-Expresiones de carácter vulgar/ coloquial: } \\
\text { ique te dé el aire!, ;va en serio! } \\
\text {-Unidades carentes de información: bueno, tío. } \\
\text {-Marcas de registro técnico: webs, ADSL, } \\
\text { gluten. } \\
\text {-Unidades léxicas relacionadas con la } \\
\text { competitividad: ser el campeón, esfuerzo, } \\
\text { trabajo duro. }\end{array}$ \\
\hline Pragmático-discursivo & $\begin{array}{l}\text {-Estrategias discursivas de carácter } \\
\text { interrogativo: ¿sabes que tu novio está } \\
\text { muy bueno?, ¿quieres ser natural? } \\
\text {-Mecanismos conversacionales } \\
\text { solidarios: ¿y esto?, ¿te la vas a poner } \\
\text { mojada? } \\
\text {-Discursos con implicaciones } \\
\text { pragmáticas sexistas: infravaloración y } \\
\text { cosificación de la mujer: contrólame, } \\
\text { protégeme, gritame. }\end{array}$ & $\begin{array}{l}\text {-Estrategias discursivas de carácter } \\
\text { exclamativo o informativo-explicativo: ia ver } \\
\text { de dónde saco yo la pasta!, ;hombres, esta es } \\
\text { vuestra crema! } \\
\text {-Mecanismos conversacionales descorteses: } \\
\text { iqué síiiit!, iqué plasta!. } \\
\text {-Discursos con implicaciones pragmáticas } \\
\text { vinculadas con la seguridad. Exhibición de } \\
\text { actitudes chulescas: ser el campeón, qué crack. }\end{array}$ \\
\hline
\end{tabular}

Tabla 4. Caracterización sociolingüística de los hablantes jóvenes en publicidad. 
En los anuncios analizados, generalmente (excepto casos puntuales) no se define con precisión la clase social de los hablantes, ni el nivel de instrucción, puesto que el interés principal radica en la identidad juvenil por encima de cualquier otro factor. Así, parte de las características lingüísticas expuestas pueden atribuirse perfectamente al habla juvenil: por ejemplo, la entonación expresiva, la inclinación por formas léxicas y expresiones de carácter coloquial, así como ciertos procedimientos gramaticales (apócope). En cuanto a la construcción de estructuras sintácticas simples, también es un rasgo del habla juvenil, pero en la mayoría de los casos debe vincularse con la brevedad propia del mensaje publicitario, ya que difícilmente se hallan discursos complejos. No obstante, es cierto que los únicos ejemplos obtenidos se encuentran en los emisores adultos, hecho que puede intuirse como un indicador de variación genolectal.

Resumiendo, más allá de las características del habla juvenil, la publicidad manifiesta evidentes diferencias generolectales. Pues el género femenino se refleja a partir de la tendencia al léxico de sentido positivo, cortés, y de mecanismos conversacionales solidarios, mientras que el masculino roza la vulgaridad y se centra en la competitividad y el poder. Lamentablemente, concluimos con la presencia del sexismo en numerosos anuncios publicitarios.

\subsection{Variación Generolectal en Hablantes Adultos}

La tercera sección del análisis, dedicada a los hablantes adultos, avala las afirmaciones declaradas en el marco teórico en relación con los fenómenos de autocorrección: "los grupos de edades intermedias, inmersos en el mundo de la competencia profesional, económica y de ascenso en la escala social, son los que se espera que presenten perfiles de autocorrección" (López Morales 1993: $50)$.

Los estereotipos adultos se orientan hacia una mayor formalidad y un descenso acusado de las marcas propias de las edades más jóvenes. No obstante, las sociedades occidentales suelen situar el envejecimiento cerca del tabú, acudiendo constantemente a la exaltación de los valores juveniles. Luego, la publicidad, próxima a las concepciones sociológicas, también es un reflejo de esta realidad; por ello, no resulta extraño ver anuncios publicitarios donde hablantes adultos producen expresiones lingüísticas asociadas al habla de los grupos más jóvenes. Por tanto, la adecuación de la comunicación publicitaria también atiende a la ideología integrada en la sociedad receptora de 
la publicidad. Así, los anuncios publicitarios, como forma de comunicación social, materializan la alabanza de las actitudes juveniles a través del uso deliberado de marcas sociolingüísticas propias de los estereotipos asociados a los hablantes más jóvenes. Por consiguiente, como demuestran los anuncios compilados en el corpus, es frecuente hallar un uso de formas apocopadas o incluso de metáforas coloquiales y de términos carentes de información entre los hablantes más adultos, entendiendo este hecho como un intento de exhibir un rejuvenecimiento del emisor por parte de los publicistas.

$\mathrm{Si}$ en los anuncios que presentaban emisores jóvenes, las variables clase social, nivel de instrucción y profesión no constituían el foco de atención de los publicistas; en los anuncios cuyos hablantes son adultos, estas variables ejercen una función determinante. Incluso, las campañas publicitarias suelen acudir a personas socialmente famosas, que generalmente también gozan de cierto prestigio lingüístico. Así, en nuestro corpus aparecen actrices como Concha Velasco o Maribel Verdú para el género femenino y periodistas como Carlos Sobera y Jesús Vázquez para el masculino.

Del mismo modo que en los capítulos anteriores, comentamos los porcentajes obtenidos, en los que se demuestra que la diferenciación generolectal disminuye considerablemente en la etapa adulta. El habla tanto femenina como masculina experimenta una evolución parecida, pues, por ejemplo, el uso de variantes lingüísticas prestigiosas aumenta en ambos casos, del mismo modo que la cortesía o la preferencia por el léxico de sentido positivo. Tampoco se aprecian diferencias destacables en el uso de intensificadores o de las unidades valorativas, sino que lo más relevante es que ambos géneros presentan una mayor tendencia al:

- Uso de las variantes de mayor prestigio: $63 \%$ en los mensajes publicitarios de emisores adultos femeninos y un $53 \%$ en los mensajes masculinos.

- Mayor cortesía, corrección y adecuación a la norma: prácticamente, ambos géneros exhiben actitudes corteses y un mensaje sociolingüístico correcto en un $70 \%$ de los anuncios analizados.

- Construcciones sintácticas complejas: las formulaciones sintácticas simples obedecen a la estructuración del mensaje publicitario. En torno al $60 \%$ de los anuncios representados por hablantes adultos emite un mensaje sintácticamente complejo.

- Preferencia por el léxico de sentido positivo: no se acude a creaciones lúdico-festivas o a expresiones vulgares que pueden afectar a la sensibilidad 
del interlocutor, sino que predomina un vocabulario positivo que rehúsa de las características negativas.

- Y una menor expresividad: ambos géneros evolucionan hacia una entonación moderada, calmada, propia de las edades adultas y alejada de la expresividad eufórica de las etapas juveniles.

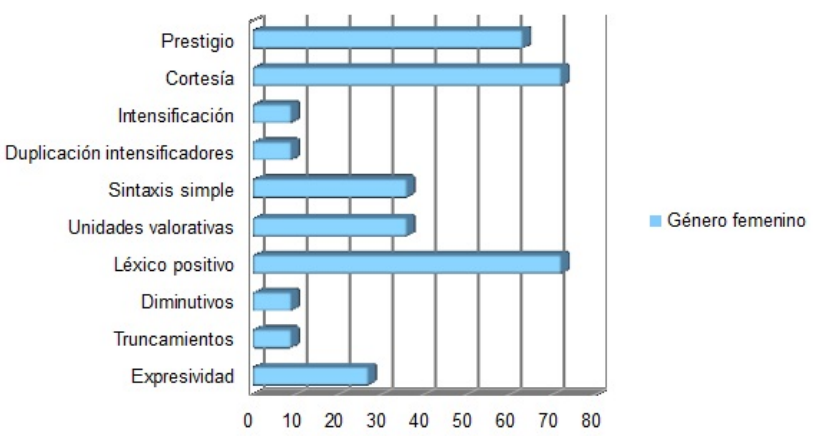

Fig. 7. Características del habla femenina en hablantes adultos femeninos.

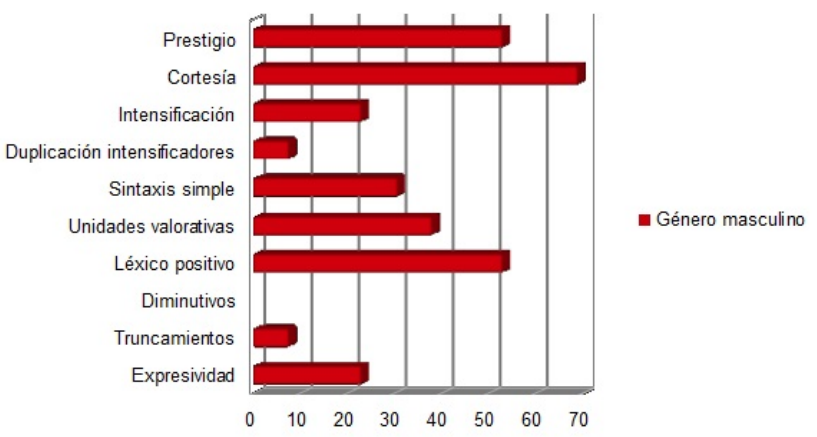

Fig. 8. Características del habla masculina en hablantes adultos masculinos. 


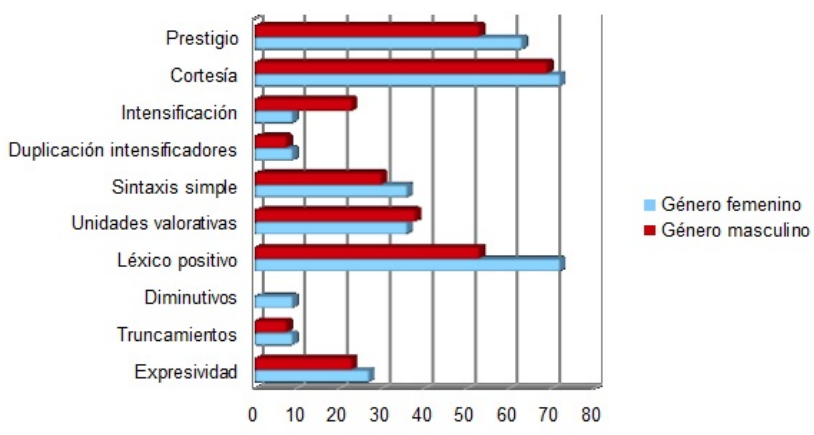

Fig. 9. Variación generolectal en los hablantes adultos.

Uno de los resultados más interesantes de nuestro análisis es la asombrosa evolución que experimenta el habla adulta en todos los niveles lingüísticos, desde el fonético-fonológico al pragmático-discursivo, no solo con la autocorrección y eliminación de las marcas lingüísticas diferenciadoras, sino también con la adopción de nuevas dimensiones como puede ser el uso de la ironía. La Tabla 5 reúne los cambios observados:

- Fonético-fonológico: en ambos géneros la entonación abandona la expresividad característica de los hablantes más juveniles en pos de una mayor moderación.

- Gramatical: tanto en los hablantes femeninos como en los masculinos, se percibe una ausencia de formas diminutivas, unidades apocopadas y recursos intensificadores, exceptuando los mensajes puntuales que desean transmitir valores juveniles.

- Léxico: no solo aumentan las unidades léxicas de mayor prestigio, sino que se produce una ausencia de los elativos léxicos propios de las etapas anteriores, y un aumento significativo de la riqueza y variedad léxica. Debe señalarse que es en la etapa adulta cuando se manifiesta una aparición más relevante de las marcas de registro.

- Pragmático-discursivo: los discursos publicitarios de ambos géneros potencian la transmisión de valores formales a partir de mecanismos conversacionales más complejos como pueden ser la ironía. Además, como ya hemos mencionado anteriormente, se experimenta una transmisión de connotaciones juveniles en ciertos casos. 


\begin{tabular}{|c|c|c|}
\hline Nivel lingüístico & Género femenino & Género masculino \\
\hline Fonético-fonológico & $\begin{array}{l}\text {-Entonación moderada, sin } \\
\text { expresividad: llega un momento en la } \\
\text { vida en que tienes que volverte } \\
\text { exigente. }\end{array}$ & $\begin{array}{l}\text {-Entonación moderada, sin expresividad: } h a y \\
\text { aspectos en nuestra salud que no podemos } \\
\text { controlar. }\end{array}$ \\
\hline Gramatical & $\begin{array}{l}\text {-Ausencia general de formas } \\
\text { diminutivas. } \\
\text {-Ausencia de intensificaciones a partir } \\
\text { de procedimientos gramaticales. } \\
\text {-Ausencia general de formas } \\
\text { apocopadas. } \\
\text {-Construcciones sintácticas } \\
\text { complejas: hay mil razones que hacen } \\
\text { de ellas unas compresas únicas }\end{array}$ & $\begin{array}{l}\text {-Ausencia de formas diminutivas. } \\
\text {-Escasas intensificaciones a partir de } \\
\text { procedimientos gramaticales, excepto casos } \\
\text { puntuales: supersilencioso. } \\
\text {-Ausencia general de formas apocopadas. } \\
\text {-Construcciones sintácticas complejas: hace } \\
\text { años salí de esta clase pensando que lo sabia } \\
\text { todo, pero comprendí que no cuando me } \\
\text { descubrieron el colesterol alto }\end{array}$ \\
\hline Léxico & $\begin{array}{l}\text {-Variantes léxicas de mayor prestigio: } \\
\text { celebrity, polución. } \\
\text {-Ausencia de elavitos léxicos. } \\
\text {-Riqueza y precisión léxicas. } \\
\text { Unidades más complejas: simbólico, } \\
\text { específico. } \\
\text {-Marcas de registro: ácido fólico, } \\
\text { grasas saturadas, ph5. }\end{array}$ & $\begin{array}{l}\text {-Variantes léxicas de mayor prestigio: } \\
\text { poliglota. } \\
\text {-Ausencia de elativos léxicos. } \\
\text {-Riqueza y precisión léxicas. Unidades más } \\
\text { complejas: revisión auditiva, sherpa, faquir. } \\
\text {-Inclinación por formas menos recientes: } \\
\text { guardameta vs portero. } \\
\text {-Marcas de registro: colesterol, vitaminas, } \\
\text { minerales, coenzima Qlo. }\end{array}$ \\
\hline Pragmático-discursivo & $\begin{array}{l}\text {-Mecanismos conversacionales } \\
\text { complejos: ironía. Por ejemplo, uso } \\
\text { de la forma diminutiva detallito para } \\
\text { aludir al Mercedes-Benz. } \\
\text {-Transmisión de connotaciones } \\
\text { formales y de valores juveniles en } \\
\text { ciertos casos. }\end{array}$ & $\begin{array}{l}\text {-Transmisión de connotaciones formales y de } \\
\text { valores juveniles en ciertos casos. }\end{array}$ \\
\hline
\end{tabular}

Tabla 5. Caracterización sociolingüística de los hablantes adultos en publicidad.

Las unidades léxicas apocopadas y diminutivas que se encuentran en los emisores adultos son ejemplos particulares que responden a la exhibición de valores y actitudes joviales. Suelen simular la comunicación familiar entre abuelos y nietos.

En conclusión, de los hablantes adultos se espera un perfil sociolingüístico formal, alejado de los rasgos lingüísticos juveniles. Así, la diferenciación 
generolectal tan intensa en las edades más cortas desciende en la edad adulta hasta llegar a una caracterización sociolingüística similar a ambos géneros. No obstante, los resultados de los análisis confirman que la publicidad exhibe las características estereotipadas propias del denominado genderlect en las distintas edades estudiadas (Zernova 2000: 1):

1. Las mujeres tienden a un discurso más "correcto", más estándar que los hombres.

2. El habla femenina se caracteriza por una mayor cortesía en comparación con la masculina.

3. En el proceso del discurso la mujer manifiesta mayor expresividad y menor seguridad que el hombre.

4. El habla femenina es menos oficial, más íntima.

\subsection{Variación Diastrática}

En cuanto a la variación diastrática, la clase media es la más representada en publicidad, con diferencia, puesto que supone un notable porcentaje de la sociedad y, por consiguiente, del público objetivo. No obstante, también encontramos, aunque en menor medida, anuncios destinados a las clases altas y bajas. Se perciben diferencias significativas entre la representación de los hablantes de clase alta y media con un nivel de instrucción elevado y profesiones que requieren un uso del lenguaje (actriz, periodista, humorista) y hablantes de clase social baja con un nivel de instrucción menor y profesiones menos prestigiosas (ganadero).

- Fonético-fonológico: se percibe una tendencia a la realización fonética relajada en las clases más bajas en comparación con la precisión fonética característica de las clases medias y altas a las que se le atribuye un grado de instrucción mayor. Además, la expresividad parece ser que es un rasgo que decrece a medida que se avanza en la escala social.

- Gramatical: las construcciones sintácticas son básicas y poco complejas en las clases bajas, materializándose mediante el escaso uso de oraciones subordinadas. En cambio, los discursos experimentan un aumento en su complejidad en los sociolectos más altos.

- Léxico: el vocabulario utilizado en los discursos publicitarios que representan a las clases bajas es de carácter coloquial, es decir, de alta frecuencia, 
y se aleja de la riqueza y precisión léxicas de las clases más altas, en cuyos mensajes no es difícil localizar marcas de registro técnico.

- Pragmático-discursivo: los discursos presentan un grado de complejidad menor en las clases bajas en contraste con los extensos discursos de las clases altas, organizados en torno al uso variado de conectores.

\begin{tabular}{|c|l|l}
\hline \multicolumn{1}{|c|}{ Nivel lingǘrtico } & \multicolumn{1}{|c}{ Clase baja } & \multicolumn{1}{c}{ Clase media y alta } \\
\hline Fonético-fonológico & -Realizaciones fonéticas relajadas. & -Realizaciones fonéticas precisas. \\
\hline Gramatical & $\begin{array}{l}\text {-Construcciones sintácticas simples: } \\
\text { esto es un campo y nosotros estamos } \\
\text { en medio. }\end{array}$ & $\begin{array}{l}\text {-Construcciones sintácticas complejas: la } \\
\text { gente nos preguntaba qué se siente al } \\
\text { conducir } \text { el nuevo Renault Megane, asi que } \\
\text { realizamos un experimento con el fin de } \\
\text { explicarlo con la ayuda de la última } \\
\text { tecnología. }\end{array}$ \\
\hline Léxico & -Léxico reducido. & $\begin{array}{l}\text {-Riqueza y precisión léxicas: poliglota, } \\
\text { polución. }\end{array}$ \\
\hline Pragmático-discursivo & $\begin{array}{l}\text {-Discursos simples: [esto es un campo] } \\
\text { y [nosotros estamos en medio] }\end{array}$ & $\begin{array}{l}\text {-Discursos complejos, organizados a partir } \\
\text { del uso de conectores: primero [fue el pan } \\
\text { blanco], luego [el integral] y ahora [qué]. }\end{array}$ \\
\hline
\end{tabular}

Tabla 6. Variación diastrática en publicidad.

\subsection{Variación Diafásica}

Por último, nos ocupamos del análisis de la variación diafásica, esto es, las "diferencias entre los tipos de modalidad expresiva, según las circunstancias constantes del hablar (hablante, oyente, situación u ocasión del hablar y asunto del que se habla" (Coseriu 1981: 12).

Es un hecho axiomático que los individuos cambian su forma de hablar según el contexto físico y humano en el que tiene lugar la comunicación. El habla, como otras formas de conducta social, se modifica y adapta a diferentes situaciones (Silva-Corvalán 1989: 87).

Examinamos el uso de estilos y registros en los mensajes publicitarios, con excepción de aquellos cuyos emisores lingüísticos son hablantes de corta edad, puesto que el desarrollo de la variación estilística se produce a partir de los 14 años aproximadamente (Labov 1964: 77-103). 
Con excepción de los niños, algunos extranjeros y sujetos que hayan sufrido daños en la corteza cerebral, todos los hablantes tienen acceso a más de un estilo lingüístico, de un registro (López Morales 1993: 43).

El estilo hace referencia "a los usos lingüísticos que se definen en función de la situación y el contexto comunicativos" (Moreno Fernández 1998: 92) y se relaciona con la escala de formalidad (Silva-Corvalán 1989: 89); mientras que por registro se entiende "la variedad de la lengua asociada a un determinado tipo de actividad" (Silva-Corvalán 1989: 89).

La variación estilística no puede comprenderse si se prescinde de la variación sociolingüística (Moreno Fernández 1998: 92), puesto que "el estilo sería una proyección de la dimensión sociolingüística" (Moreno Fernández 1998: 95); "cada sociolecto tiene su variación diafásica" (López Morales 1993: 44).

Establecer un número concreto de estilos es muy complejo, ya que los límites entre ellos son muy difusos (Moreno Fernández 1998: 97). Así, hay autores como Joos (1959), citado por López Morales (1993: 46-47), que establecen cinco estilos:

1. íntimo,

2. casual,

3. consultativo,

4. formal

5. y congelado;

mientras otros, como Labov (1966: 60-88) conciben solo tres:

1. informal o vernáculo (casual speech),

2. cuidado o formal (formal speech)

3. y espontáneo (spontaneus speech).

Ante las diferentes posturas, nuestro análisis se posiciona por la clasificación estilística propuesta por Labov (1966: 60-88), estableciendo así la siguiente escala ordenada de menor a mayor formalidad:

1. informal;

2. coloquial;

3. formal. 
Respecto al registro, donde destacan los trabajos de Michael Halliday (1964) con su teoría del registro, se han determinado tres dimensiones que intervienen en su variación (Moreno Fernández 1998: 94):

1. El campo del discurso: se refiere al contexto en que se hace uso de la lengua y depende del tema tratado (discusión científica, vida cotidiana) y de la actividad que desarrollan el hablante y sus interlocutores (por ejemplo, labores domésticas, seminario académico).

2. El modo del discurso: se refiere al canal de comunicación, al medio o "modo" en que se produce la actividad lingüística, incluyendo la distinción primaria entre lengua hablada y lengua escrita.

3. El tenor o estilo del discurso: se refiere al tipo de relación que existe entre los participantes en un proceso comunicativo; a este respecto, la distinción primaria y fundamental es la de estilo educado y estilo coloquial.

Apuntamos que para esta sección del análisis se ha prestado especial atención a la proyección de la variación sociolingüística en las diferencias de estilo. Tras estudiar los factores personales (hablante, audiencia) y no personales (discurso, contexto) expuestos por Bell (1984: 145-204), extraemos los siguientes resultados:

1. Las diferencias generolectales se dibujan también en el estilo: la mayor cortesía del género femenino se proyecta en una menor tendencia a la informalidad, mientras que el género masculino presenta estilos más informales.

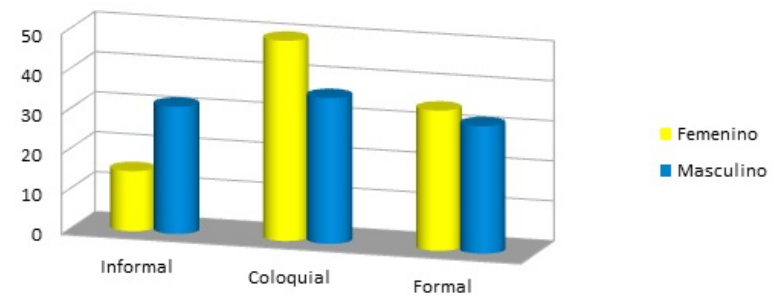

Fig. 10. Proyección de la variación generolectal en el estilo. 
2. Las diferencias genolectales se manifiestan en el estilo: los hablantes jóvenes se inclinan hacia la informalidad, mientras que los adultos prefieren el uso de un estilo más formal. Este hecho puede relacionarse directamente con los fenómenos de autocorrección y con la preocupación de las generaciones adultas por el ascenso social y profesional.

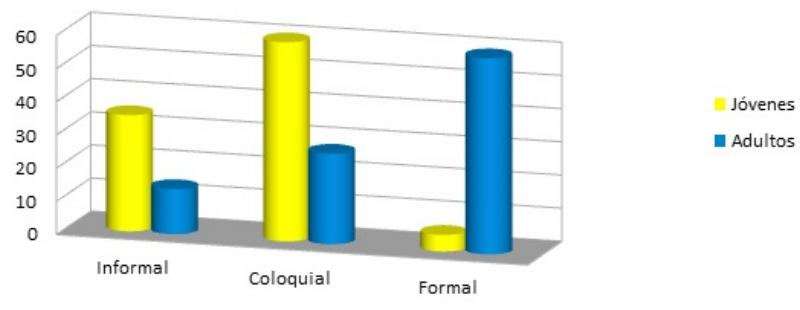

Fig. 11. Proyección de la variación genolectal en el estilo.

3. En cuanto a la variación diastrática, teniendo en cuenta la clase social, el nivel de instrucción y la profesión, se percibe la expresión:

- Clase social más alta $\rightarrow$ producto prestigioso $\rightarrow$ mayor formalidad

- Clase social más baja $\rightarrow$ producto menos prestigioso $\rightarrow$ menor formalidad

Por consiguiente, no resulta extraño que los productos que gozan de prestigio en su ámbito comercial presenten un estilo más formal que aquellos menos prestigiosos. Así pues, a modo de ejemplo, Bosch, Mercedes-Benz, Renault, Gerblé, Oroweat y El Pozo hacen uso de un estilo más formal que, por ejemplo, Rastreator.com, Qé crack o Aldi supermercados.

A continuación, nos ocupamos del registro a través del estudio de su función en el mensaje publicitario. Independientemente del modo y estilo, categorizamos los distintos anuncios a partir del concepto campo del discurso. Considerando la temática tratada, obtenemos la siguiente clasificación: electrónica, alimentación, medicamentos y productos cosméticos y economía. Con la finalidad de garantizar la sistematicidad, ejemplificamos las marcas de registro particulares de cada mensaje publicitario a través de léxico específico:

- Electrónica: red de superbanda ancha, fibra simétrica, megas, títulos en $H D, 4 G$ plus, TV premium, fibra óptica, smartphone, tablet, ADSL, fibra. 
- Alimentación: índice glucémico, mineralización, impurezas, sodio, l-casei, vitamina $B 6$, grasas saturadas.

- Medicamentos y productos cosméticos: célula, minerales, coenzima Q10, vitaminas grupo B, hierro, ácido fólico, flurbiprofeno, ph 5, dexpantenol.

- Economía: cuenta pensión, comisión, TAE.

Percibimos que la presencia de un vocabulario técnico cumple una doble función de distinto nivel:

1. Función informativa: situada en el plano superficial, consiste en transmitir, con precisión, los detalles del producto o servicio al público objetivo.

2. Función persuasiva: en un plano más profundo, se aporta un valor añadido a partir de las implicaciones del léxico empleado: por ejemplo, unidades léxicas como smartphone o tablet implican cierto prestigio sociocultural.

\section{Conclusiones}

El análisis realizado ha puesto de manifiesto que la variación generolectal se representa en la publicidad con intensidad en las generaciones más jóvenes y decrece paulatinamente en las edades adultas. Estos resultados están en consonancia con las reflexiones de Cameron (1993), quien tras el estudio de la relación entre el género y la edad indicó que las diferencias generolectales presentan su máximo en las edades más jóvenes y experimentan un decrecimiento paulatino en las etapas adultas.

A pesar de las significativas diferencias generolectales, defendemos que parte de la variación observada procede de la conjunción de otros parámetros sociales como la edad o la clase social. La influencia de las distintas variables sociales es difícil de delimitar con precisión.

Respecto a la variación genolectal, podemos decir que las diferencias de edad se reflejan en los anuncios publicitarios mediante el uso de los rasgos propios del habla juvenil y su ausencia en las edades adultas, aunque se detectan casos puntuales del uso de marcas juveniles en el habla adulta con la finalidad de transmitir un mensaje jovial o simular la conversación con los hablantes de más corta edad. 
Referente a los fenómenos de covariación en los distintos niveles lingüísticos teniendo en cuenta las variables sociales podemos decir que la variación diastrática -incluyendo en ella el análisis de la clase social, el nivel de instrucción y la profesión- determina esencialmente el nivel léxico y pragmático-discursivo de los anuncios publicitarios.

En cuanto a la variación diafásica, el análisis realizado ha puesto de manifiesto que la variación generolectal, genolectal y diastrática se proyectan en diferencias de formalidad estilística. Se observa mayor formalidad en habla femenina que en la masculina. En general, las mujeres frente a los hombres usan un mayor número de variantes normativas, correctas y corteses. Los hablantes jóvenes presentan mayor inclinación a la informalidad frente a los adultos que prefieren el uso de un estilo más formal. Por último, los estilos más formales se asocian a las clases sociales altas, mientras que los estilos menos formales predominan en las clases más bajas. Por otra parte, el registro responde a una doble función en el mensaje publicitario: una función informativa, ubicada en un nivel superficial, que consiste en la explicación o transmisión de los detalles del producto o servicio anunciado, y una función persuasiva, situada en un nivel más profundo, que puede vincularse con la suma de valor, puesto que tales marcas de registro implican cierto prestigio sociocultural.

El análisis realizado también ha puesto de manifiesto que la comunicación publicitaria intenta reflejar en la mayoría de anuncios, aunque no siempre con éxito, los principios sociolingüísticos relacionados con la covariación entre las variables lingüísticas y las variables sociales y contextuales. No obstante, consideramos que la adecuación sociolingüística en cuanto a la variación generolectal, genolectal y diastrática es satisfactoria de manera general en los distintos anuncios analizados, aunque percibimos que las caracterizaciones se construyen con fundamentos estereotipados y muestra de ello son los anuncios que transmiten contenidos sexistas, ya que contribuyen a la creación y a la difusión de determinados roles socioculturales, contrarios a la constante lucha por la igualdad. Tal vez, una revisión de los pilares teóricos permitiría una mayor perfección de la adecuación de los mensajes publicitarios en relación con los fenómenos de covariación sociolingüísticos.

Creemos que la publicidad, con su inmensa capacidad para influir en la sociedad a través de los medios masivos como la televisión, debería erradicar no solo cualquier connotación sexista, sino también el uso de determinados estereotipos sociolingüísticos que no responde de manera coherente a la rea- 
lidad, ya que fomentan la diferenciación y la construcción, desafortunada, de ciertos papeles sociales inadecuados.

\section{Futuras Líneas de Investigación}

Por último, considerando que la publicación supone una breve exposición de un asunto que requiere un tratamiento más extenso, proponemos varias líneas de investigación para el futuro:

1. Estudio comparativo del reflejo de la variación sociolingüística (diatópica, diastrática y diafásica) en los anuncios publicitarios de comunidades de habla pertenecientes a distintas culturas.

2. Análisis del uso del lenguaje metafórico en los anuncios publicitarios desde una perspectiva cognitiva.

3. Observación del impacto sociológico que supone el uso de estereotipos sociolingüísticos en la publicidad.

4. Estudio de la difusión de connotaciones sexistas a partir de la variación generolectal manifestada en la publicidad.

5. Reflexión sobre la implicación de las variables sociales en la variación estilística y el registro de los anuncios publicitarios.

6. Análisis profundo de la variación sociolingüística exhibida en la comunicación no verbal de los anuncios.

\section{Bibliografía}

1. Aeker, D. A., \& Myers, J. G. (1984). Management de la publicidad. Barcelona: Hispano Europea.

2. Alba, O. (1990). Variación fonética y diversidad social en el español dominicano de Santiago. Santiago: PUCMM.

3. Alexander, R. S. (1963). Marketing definitions: a glosary of marketing terms. Chicago: American Marketing Association.

4. Alvar, M. (1972). Niveles socio-culturales en el habla de las Palmas de Gran Canaria. Las Palmas de Gran Canaria: Cabildo Insular.

5. Anula, A. (1998). El abecé de la Psicolingüistica. Madrid: Arco Li-bros.

6. Bell, A. (1984). Language style as audience design. Language in Society, 13: 145-204.

7. Benavides, J. (1977). Lenguaje publicitario: hacia un estudio del lenguaje en los medios. Madrid: Síntesis. 
8. Bentivoglio, P. \& Sedano, M. (1993). Investigación sociolingüística: sus métodos aplicados a una experiencia venezolana. Boletín de Lingüistica, 8: 3-36.

9. Bernstein, B. (1958). Some sociological determinants of perception. British Journal of Sociology, 9: 159-174.

10. Bloomfield, L. (1933). Language. New York: Holt.

11. Borrego, J. (1981). Sociolingüistica rural. Investigación en Villadepera de Sayago. Salamanca: Universidad de Salamanca.

12. Bright, W. (1996). Sociolinguistics. Proceedings of the UCLA Socio-linguistics Conference. The Hague: Mouton.

13. Calero Fernández, M.A. (1999). Sexismo lingüistico: análisis y propuestas ante la discriminación sexual en el lenguaje. Madrid: Narcea.

14. Cedergren, H. (1983). Sociolingüística. In López Morales, H., Introducción a la lingüistica actual (pp. 147-166). Madrid: Playor.

15. Chambers, J. K. (1995). Sociolinguistic Theory: Linguistic Variation and Its Social Significance. Oxford: Blackwell.

16. Chambers, J. K. \& Trudgill, P. (1980). Dialectology. Cambridge: Cambridge University Press.

17. Coseriu, E. (1981). Los conceptos de "dialecto", "nivel" y "estilo" de lengua y el sentido propio de la dialectología. Lingüistica Española Actual, 3: 1-32.

18. Currie, H. C. (1952). A projection of socio-linguistics: the relationship of speech to social status. Southern Speech Journal, 18: 28-37.

19. Etxebarría, M. (1985). Sociolingüística urbana. El habla de Bilbao. Salamanca: Universidad de Salamanca.

20. Etxebarría, M. (1995). Bilingüismo en el estado español. Bilbao: FBV.

21. Ferrer, E. (1980). La publicidad. México: Trillas.

22. García, N. (2009). La mujer en la publicidad. Trabajo Final de Máster. Salamanca: Universidad de Salamanca.

23. Halliday, M. A. K (1964). Comparison and translation. In Halliday, M. A.K., McIntosh, M. \& Strevens, P., The linguistic sciences and language teaching. London: Longman.

24. Hjelmslev, L. (1947). Structural analysis of language. Studia Linguistica, 1: 6978.

25. Hockett, C. (1958). A course in modern linguistics. New York: Macmillan.

26. Hudson, R. (1981). La sociolingüistica. Barcelona: Anagrama.

27. Labov, W. (1964). Stages in the acquisition of standard English. In Shuy, R., Social Dialects and Language Learning, Champaign, III (pp. 73-107). National Council of Teachers of English.

28. Labov, W. (1966). Hypercorrection by the lower middle class as a factor in linguistic change. In Bright, W., Sociolinguistics. Proceedings of the UCLA Sociolinguistics Conference (pp. 84-102). The Hague: Mouton

29. Labov, W. (1966). The social stratification of English in New York City. Washington: Center for Applied Linguistics. 
30. Labov, W. (1972). Sociolinguistic patterns. Philadelphia: University of Pennsylvania Press.

31. Labov, W. (1973). The place of linguistic research in American Society. In Linguistics in the 1970's. Washington: Center for Applied Linguistics.

32. Labov, W. (1978). Where does the sociolinguistic variable stop? A reply to B. Lavandera. Texas Working Papers in Sociolinguistics, 44. Austin: South West Educational Development Laboratory.

33. Labov, W. (1996). Principles of linguistic change. Oxford: Blackwell.

34. Lavandera, B. (1984). Variación y significado. Buenos Aires: Hachette.

35. Ley general de publicidad. Ley 34/1988 de 11 de noviembre.

36. López Morales, H. (1983). Estratificación social del español de San Juan de Puerto Rico. México: Universidad Nacional Autónoma de México.

37. López Morales, H. (1993). Sociolingüistica. Madrid: Gredos.

38. López Morales, H. (2005). Sociolingüística del tabú. El caso de Puerto Rico. Madrid: Editorial Playor.

39. Madrid, S. (2001). La variación sociolingüística en publicidad. Análisis sociolingüístico de textos publicitarios televisivos. Revista Electrónica de Estudios Filológicos, 1: 1-51.

40. Martín Butragueño, P. (1992). Hacia una tipología de la variación gramatical en sociolingüística del español. Nueva Revista de Filología Hispánica, 42: 29-75.

41. Martínez Celdrán, E. (1988). Fonología general y española. Barcelona: Teide.

42. Meillet, A. (1928). Esquisse d'un histoire de la langue latine. Paris: Hachette.

43. Michael, J. (1962). The construction of the social class index. In Codebook for the Mobilization for Youth. New York: Mobilization for Youth.

44. Moreno Fernández, F. (1988). Sociolingüistica en EE.UU. 1975-1985. Guía bibliográfica crítica. Málaga: Agora.

45. Moreno Fernández, F. (1998). Principios de sociolingüistica y sociología del lenguaje. Barcelona: Ariel.

46. Ortega, E. (2004). La comunicación publicitaria. Madrid: Pirámide.

47. Penedés, I. (1999). La enseñanza de las unidades fraseológicas. Alcalá de Henares: Universidad de Madrid.

48. Pérez F. (2004). La fraseología castellana en torno a trabajo y su familia léxica: ensayo de análisis, clasificación y visión del mundo. Navarra: Universidad de Navarra.

49. Perissinotto, G. (1972). Distribución demográfica de la asibilación de vibrantes en el habla de la ciudad de México. Nueva Revista de Filología Hispánica, 21: $71-79$.

50. Quilis, A. (1992). La lengua española en cuatro mundos. Madrid: Mapfre.

51. Real Academia Española (2014). Diccionario de la lengua española.

52. Reid (1978). Social and stylistic variation in the speech of children: some evidence from Edingburgh. In Trudgill, P., Sociolinguistic Patterns of British English (pp. 158-171). Londres: Arnold. 
53. Robinson, W. P. (1978). Lenguaje y conducta social. México: Trillas.

54. Romaine, S. (1984). The Language of Children and Adolescents. The Acquisition of Communicative Competence. Oxford: Blackwell.

55. Samper, J. A. (1990). Estudio sociolingüistico del español de Las Palmas de Gran Canaria. Las Palmas: La Caja de Canarias.

56. Sánchez, R. (1979). Introducción a la teoría de la publicidad. Madrid: Tecnos.

57. Sankoff, D. (1978). Linguistic Variation. Models and methods. New York: Academic Press.

58. Saussure, F. de. (1919). Cours de linguistique générale. Paris-Laussane: Payot.

59. Silva-Corvalán, C. (1989). Sociolingüistica: teoría y análisis. Madrid: Alhambra.

60. Trudgill, P. (1974). The social differentiation of English in Norwich. Cambridge: Cambridge University Press.

61. Ueda, H. (1982). Comparación de las formas vocativas españolas y japonesas. Atributos del hablante, del interlocutor y sus relaciones. Area and Culture Studies, XXXII.

62. Weinreich, U., Labov. W. \& Herzog, M. (1968). Empirical fundations for a theory of language change. In Directions for historical linguistics: A symposium (98-188). Austin: The University of Texas Press.

63. Wodak, R. \& Benke, G. (1997). Gender as a Sociolinguistic Variable: New Perspectives on Variation Studies. In Coulmas, F., The Handbook of Sociolinguistics (pp. 127-150). Oxford: Blackwell.

64. Wolfram, W. (1989). Structural variability in phonological development: final nasals in Vernacular Black English. In Fasold, R. \& Schiffrin, D., Language Change and Variation (pp. 310-332). Amsterdam: John Benjamins.

65. Zenith Media (2016). Índice Zenith. blogginzenith.zenithmedia.es

66. Zernova, Y. (2000). Algunos factores diferenciadores del habla masculina y femenina. San Petersburgo: Universidad Estatal de San Petersburgo.

\section{Author's Biodata}

Damián Morales Sánchez cursó el Bachillerato Humanístico en La Salle Tarragona durante los años 2010-2012 con el reconocimiento del premio extraordinario por Matrícula de Honor. En 2010 alcanzó el nivel B1 en inglés a través del Preliminary English Test reconocido por University of Cambridge. Atraído por los saberes humanísticos y con una firme vocación docente, se formó en Lengua y Literatura Hispánicas en la Universitat Rovira i Virgili durante los años 2012-2016, obteniendo la calificación de Matrícula de Honor en las prácticas externas de docencia realizadas en el Institut Pons d'Icart. Participó como ponente invitado por la Universitat Rovira i Virgili en la jornada de Hispánicas en el Insti celebrada el 14 de mayo de 2016. Asimismo, motivado por el crecimiento personal, estudió el curso de desarrollo laboral 
y personal Entrenamiento emocional impartido por la Universitat Oberta de Catalunya en el año 2014, obteniendo la calificación de Matrícula de Honor. 